\title{
The Role of Emotions in Intercultural Business Communication: Language Standardization in the Context of International Knowledge Transfer.
}

Qiu Wang (a), Jeremy Clegg (b), Hanna Gajewska-De Mattos (b), Peter Buckley (b)

(a) Department of Strategy, Management \& Marketing, Birmingham City Business School, Birmingham City University, Birmingham, B4 7BD, United Kingdom

(b) Centre For International Business, Leeds University Business School, University of Leeds, Leeds, LS2 9JT, United Kingdom

Abstract: We examine language standardization in a multinational enterprise in the context of international knowledge transfer treated as an act of communication. Based on psychological theories of emotions and a qualitative study of a Chinese owned company with English as a working language, we find that both native and non-native English-speakers experience anxiety in intercultural communication. This triggers emotions that are culturally predisposed affecting communication behavior. We provide a framework within which intercultural business communication takes place and demonstrate the intermediating role that emotions play when language is standardized.

Key words: Emotions; Intercultural business communication; Language standardization; MNE knowledge transfer 


\section{Introduction}

Multinational enterprises (MNEs) face communication difficulties because they span language groups. One solution to this is to introduce a common working language across the enterprise. Crudely, this could be viewed as a means of reducing transaction costs including the specific case of international technology transfer. However, this approach presents problems, both in practice and in theory, because it ignores the human response to enforced standardization of language including the participants' emotions. This paper examines emotions in intercultural business communication resulting from language standardization, as a natural experiment. We make instrumental use of international knowledge transfer to discover the emotional impact on individuals. Our novel research design utilizes a single case of a multinational headquartered in China with subsidiaries in the USA, Europe and Australia. Based on appraisal theory (Ellsworth \& Scherer, 2003) we propose that human beings generate emotions according to cultural predisposition in response to personal concerns arising within intercultural communication. The central idea of appraisal theory is that emotion occurs when individuals appraise features of an event in relation to personal concerns (Ellsworth \& Scherer, 2003). The core appraisal pattern that constitutes emotion is universal, but the appraised meaning attached to an event varies culturally. Appraisal theory enables us to assess the impact of language standardization on emotional reactions that then affect the outcome of the communication process.

We theorize that the emotional impact from the intercultural communication process may be positive or negative. By pointing to the importance of context surrounding the individual, and his or her cultural predisposition, we offer a potential route to resolving a conflict within the literature. The literature suggests positive outcomes from language standardization, including cost reduction of codifying and transferring knowledge (Buckley et al., 2005; Peltokorpi \& Yamao, 2017), creating a common dominant logic for employees to 
enhance collective goals achievement (Verbeke, 2010; Yamao \& Sekiguchi, 2015), and fostering a sense of belonging to "one global family" (Piekkari et al., 2005; Neeley \& Dumas, 2016). The negative findings are exclusion from knowledge exchange and relationship building of less fluent staff (Goodall \& Roberts, 2003), status gain and "language gatekeeping" by more fluent staff (Zander et al., 2011), misinterpretation of meanings of the message (Brannen, 2004), perceptions of in-group and out-group status based on language proficiency (Peltokorpi \& Yamao, 2017) leading to "shadow structures" (Marschan-Piekkari et al., 1999). These conflicting findings in the received literature suggest that the problem has not been adequately investigated.

Contrary to the previous literature, we focus on both the native and non-native English speakers and their emotions generated in the process of intercultural communication. From the point of view of a native speaker, emotions are generated when a non-native speaker fails to communicate effectively in the native speaker's own language. From the point of view of the non-native speaker emotions arise from the frustration in a lack of command of the lingua franca of the company. The nature of emotions generated are different on both sides and are contingent on the choice of language and would be different were a different language to be chosen.

The core thesis of this paper is that successful intercultural communication cannot be achieved unless the emotional impact of key factors surrounding that communication are considered. The context surrounding interpersonal communication includes the language of transmission. Standardizing language (e.g. on English) in a firm or other institution elicits emotional responses. These emotional responses can be analyzed as playing an intermediating role (by which we mean that this could also have a negative effect, as in interference) between the act of standardizing language and its results - on achieving organizational goals, reducing costs and building communities. These emotional responses are partly culturally conditioned 
(through cultural predisposition and as a response to the specific behavior in the other culture). Both the relationship between cultural background and language change and that between language change and emotional response are neglected factors in the process of intercultural communication.

Our research is based on a qualitative study of international knowledge transfer in a large I.T. service company headquartered in China, which designated English as its official working language for global team members. Based on qualitative data from 60 in-depth interviews, a 9-month long period of participant observation fieldwork and various company documents, we find that both native and non-native English-speaking MNE staff experience feelings of anxiety when using English as the lingua franca. As they attempt to cope with language asymmetry, felt anxiety develops into a cultural predisposition towards specific emotions depending on their cultural background as well as the emotional response to the specific behavior in the other culture. Language-induced emotions change the individual intercultural communication practice in ways that are consistent with the appraisal theory of the trigger emotions.

This paper advances the theoretical conceptualization and understanding of intercultural communication by examining the emotional processes of individuals' reactions towards language standardization in knowledge transfer in a multinational enterprise (MNE). We define emotion as "a mental state of action readiness that arises from cognitive appraisal of events or thoughts; has a phenomenological tone; is accompanied by physiological processes; and is often expressed physically" (Bagozzi et al., 1999, p. 184). Knowledge transfer is defined as "the process through which one unit is affected by the experience of another" (Argote \& Ingram, 2000, p. 151). The competitive advantage of a MNE derives primarily from its ability to transfer knowledge across its geographically dispersed units (Kogut \& Zander, 1993, and 1996). Given that much knowledge in MNEs is closely embedded in its sociocultural 
environments (Hong \& Nguyen, 2009), the transfer of knowledge requires the use of language to communicate and generate its meaning in distinct "knowledge contexts" (Brannen \& Doz, 2010, p. 242). In response, an increasing number of MNEs have adopted English as common corporate language regardless of the location of their headquarters (Harzing \& Pudelko, 2014). However, MNE knowledge transfer often involves organizational members with varying levels of common language proficiency, with the most prominent gap being between native English speakers and non-native English speakers (Henderson, 2005).

Research shows that the disparity of corporate language skills can cause breakdown in meaning co-construction, generating a range of emotional challenges that affect both the function and relational dimension of intercultural collaboration (Aichhorn \& Puck, 2017). Moreover, through its relationship with "social identity", "trust" and "power contest", language standardization is found to exacerbate fault lines between native and non-native English speakers (Neeley et al., 2012), acting as a "lightening rod" for intense emotions that further compound inter-cultural communication (Hinds et al., 2014). From this perspective, language asymmetries set up by MNE knowledge transfer provide an opportunity to explore the emotional reactions towards language standardization in an interactive, intercultural context, and the emotional ramifications on communicative practice for MNE performance (Brannen et al., 2014). Therefore, in addition to our overarching research question ("What is the role of emotions in intercultural communication?") we ask the following specific research questions: 1) What are individual emotional responses to English as a corporate lingua franca within MNE knowledge transfer process? and 2) How does culture affect these individual responses? We answer these research questions by integrating two strands of theoretical literature: the appraisal theory of emotion and the cultural predisposition of emotional experience.

\section{MNE communication and language standardization - Received theory.}


Communication is a purposive event involving the exchange of messages between two or more people and the creation of meaning (Tubbs \& Moss, 2003). By implication, communication remains incomplete until the receiver attends, understands and responds to the message in the way that is relatively similar to what was intended by the sender. Following an interpretive approach (Blum, 1969), communication scholars such as Thompson (2003) and West and Turner (2003) argue that a focus on meaning co-creation augments the dominant functional model of communication (e.g., Shannon \& Weaver, 1949) by highlighting the relational, dynamic and context-dependent nature of communication process.

Language is central to communication because it represents a formalized system that connects signs to meaning. Through a set of linguistic resources (i.e., phonological, syntactic, grammatical, and semantic), language enables people to articulate internal thoughts, express them to others and facilitates common understanding of social activity (Crystal, 1997). Moreover, as an embodiment of culture which is defined as "a system of meaning and practice shared by members of a community" (Geertz, 1973, pp. 12-13; Fiske et al., 1998), language and culture are interrelated. Both are learned and passed down from one generation to the next through human interaction.

Culture provides meaning for the message encoded via language (Jiang, 2000), influences linguistic style in language use (Maass et al., 2006), and determines the norm of a speech community on what constitutes a good communicator for a particular purpose (Kim \& Gudykunst, 1988). On the other hand, language provides the symbols to facilitate the expression of cultural meaning. Following a weak form of the Sapir-Whorf hypothesis (Sapir, 1912; Whorf, 1940), language also functions as a vital social-cultural source to affect how members of group see and make sense of the environment around them, and how they interact with each other (Duranti, 1997). Given the increasing evidence demonstrating the interrelated nature of language and culture (Jiang, 2000; Ji et al., 2004; Joshi \& Lahiri, 2014), researchers 
across different disciplines advocate a more integrative study on their combined, albeit distinctive, impacts on the communication process (Tenzer et al., 2017).

Communication in MNEs is especially subject to the "dual impact" of language and culture as it often involves interaction between people of diverse cultural backgrounds speaking distinct native languages (Peltokorpi, 2010, p.176). This creates inherent uncertainty in the meaning and co-construction of joint work, such as knowledge transfer (Taylor \& Osland, 2003). In response, top management in many MNEs designate English as a common corporate language to facilitate in-house communication between headquarters and foreign subsidiaries (Harzing \& Pudelko, 2013). The assumption is that the dominance of English in international business provides one of the "easiest" communicative interventions to form "a universal community of mutual understanding" (Janssens \& Steyaert, 2014 p. 632). Indeed, several IB studies show that a shared language could reduce cost of codifying and transferring the knowledge from or to headquarters (Buckley et al., 2005; Peltokorpi \& Yamao, 2017), create a common dominant logic for employees to act in a unified manner, thus enhancing collective goals achievement (Verbeke, 2010; Yamao \& Sekiguchi, 2015) and foster a sense of belonging to "one global family", which is central to an inclusive corporate culture (Piekkari et al., 2005; Neeley \& Dumas, 2016).

In contrast, it was also found that the decision to instill English as corporate language seems to generate a number of problems. As observed by Fredriksson et al. (2006), there are significant discrepancies between a formal language standardization policy and an employee's daily communication patterns within MNEs. Employees with limited English skills tend to refrain from company communication in order to avoid being judged as incompetent. As a result, they may be excluded from critical knowledge exchange and relationship building despite their valuable technical skills (Goodall \& Roberts, 2003). The native speakers or employees who are fluent in English, on the other hand, may experience status gain but feel 
burdened with the obligation of "language gatekeeper" rather than concentrating on their own designated tasks (Zander et al., 2011).

Moreover, these linguistically capable staff might not accurately interpret, or even notice, new meanings of the message in intercultural communication as the mandated language becomes a signifier and not the signified through reconceptualization (Brannen, 2004). For example, Abrams et al.'s (2003) study on a multicultural project team shows how members applying different meaning to the same English words lead to failure of understanding and problems in achieving the collective goal.

Finally, as a salient marker of social identity in MNE communication, the variability of common language proficiency shapes the employee's perception of in-group and out-group status (Peltokorpi \& Yamao, 2017). If not managed well, these language-based clusters will cast "shadow structures" that distort the communication pattern and community building intended by the English-only policy (Marschan-Piekkari et al., 1999a).

Taken together, research on the consequence of language standardization for MNE communication remains ambivalent, reflecting the multifaceted nature of language in international business (Brannen et al., 2014). This complexity necessitates further research on the lived experience and communication strategy of MNE employees with regard to a language mandate (Stayaert et al., 2011). As stated by Marschan-Piekkari et al. (1999b, p. 382), "at a base level, language is an issue concerning individuals and their competence; companies do not have languages, people do".

To obtain an "up-close and personal" (Brannen \& Doz, 2010) understanding of an English-language mandate, a substantial research effort has been devoted to examine cognitive factors such as relative difference in thinking shaped by inherent structural variation between the communicator's native language and the lingua franca (Joshi \& Lahiri, 2014), high memory 
load in processing a foreign language (Volk et al., 2014) and cognitive disconnection from certain mental constructs encoded in the native language when switching to a different language (Hadjichristidis et al., 2017). However, the emotional ramifications of using English as a lingua franca have been largely neglected by the research on micro-foundation of MNE communication (Aichhorn \& Puck, 2017).

Following "the affective revolution" in organizational behavior research (Gooty et al., 2009), IB researchers have recently started to explore the emotional challenge of language standardization. The findings suggest that negative emotions induced by a corporate lingua franca lead to a destructive cycle of intercultural collaboration, as the individual tends to cope with language-related distress by shifting their distress to the other party who, in turn, reacts negatively and perpetuates a disruptive communication pattern (Neeley et al., 2012). Unlike a cognitive challenge, the difficulty of describing and communicating emotions, particularly in a foreign language, makes it even more challenging to break the vicious communication cycle (von Glinow et al., 2004). For instance, Hinds et al.'s (2014) ethnographic study of multilingual teams in a large global company notes that language-induced emotions also change the communicative behavior of those who are more cognitively capable of addressing language difference - such as the staff with a high or near-native command of English. Tenzer et al. (2014) explain that once emotions are running high, people tend to spontaneously switch to their mother tongue in intercultural communication but thus trigger feeling of "irritation" "discomfort" and "suspicion" in their foreign colleagues.

Although a selective number of international business studies began to bring the emotional dimension of intercultural communications to the fore, the existing research effort is still fragmented in its conceptualization and theoretical development. First, most studies lack a theoretically grounded definition of emotion, offering little explanation of what makes people emotional about language mandate for MNE communication. This is important given that 
emotion is a situational response to a specific target, rather than a trait or personality that represents a fixed, predictable affective reaction across a variety of events (Barsade \& Gibson, 2007). For instance, research shows that intercultural anxiety also impacts individuals who are characteristically not anxious (Stephan et al., 1995).

Second, most research tends to aggregate discrete emotional experiences induced by a corporate language mandate (i.e. English) into "anxiety" or "distress". The individual protagonist's negative feelings are limited by successful intercultural communication (Gudykunst \& Kim, 2002) and one possibility of achieving this is the use of a common language of communication (i.e., English) which can carry a positive emotional response to bridge the communication gap (Vaara et al., 2005). Finally, we know little about how specific emotions experienced by individuals with diverse cultural backgrounds influence their crossborder communication behavior.

In contrast, the literature on cultural psychology shows that emotional experiences are significantly shaped by the individual's cultural background (Mesquita \& Boiger, 2014). Indeed, Aichhorn and Puck (2017) speculate that the emotional impact of language standardization on MNE's communication is particularly acute in cultures with a high level of uncertainty avoidance, although without providing sufficient empirical evidence. Taken together, current IB research has not fully explored the nature and function of language-induced emotion in relation to communication in MNEs. For this reason, we turn to psychology where the study of human emotion is well established. Figure 1 summarizes the standard model of language standardization underlying the intercultural communication process within an MNE.

Insert Figure 1 about here 


\section{Psychological theory of emotion.}

\subsection{Psychological theory of emotion - received theory.}

As defined in our introduction, emotion is "a mental state of action readiness that arises from cognitive appraisal of events or thoughts; has a phenomenological tone; is accompanied by physiological processes; and is often expressed physically" (Bagozzi et al., 1999, p. 184). This definition highlights the syndrome-like property of emotions as involving the synchronized, multi-component changes in response to a relevant event (Scherer, 2005). Corresponding to different functions, the components of an emotion consist of a) evaluation of a situation, b) somatic symptom, c) facial and vocal expression, d) motivation to take certain action and e) subjective feeling or the awareness of bodily sensation described by the individual (Lazarus, 1991). The coherence of these changes as an adaptive strategy linking perception of events to subjective experience and to behavioral response is what gives the whole process emotional quality (Frijda, 2007). Such synchronized, situational reactions also differentiate emotion from the more enduring mood or state that refers to diffused, predictable affective reactions across a variety of events (Barsade \& Gibson, 2007, Mulligan \& Scherer, 2012). Hence it is important to examine the antecedents, process and consequences of individual emotional reactions towards a specific event of communication within a MNE.

Appraisal theory is more relevant to analyze and explain different emotions in the MNE communication process. The core idea of appraisal theory is that emotion occurs when individuals appraise features of the event in relation to their personal concerns (Ellsworth \& Scherer, 2003). Related to, but different from, cognition, that indicates the mental action of acquiring information, appraisal is seen as an individualized meaning analysis of a person's needs, goals and ability in relation to a relevant event. As captured in the notion of "relevance 
detector" (Frijad, 1986), appraisal can help to explain what makes people feel emotional about intercultural communication.

Furthermore, appraisal theory proposes a set of core dimensions that determine the type of emotions. We use Roseman's (2013) version of appraisal dimensions, which systematically differentiates 17 discrete emotions in terms of their adaptive functions. They include novelty, motive consistent/inconsistent, appetitive/aversive, control potential, probability and instrumental/intrinsic problems. For instance, "anger" is associated with the appraisal of an event perceived as high in novelty and deserving of more attention, something obstructive to the appraiser's goal, and a strong sense of control to cope with an instrumental problem (Roseman, 2013). The results of this analysis are summarized in the individual's consciousness as a core relational theme (Smith \& Lazarus, 1993), and constitute the feeling or subjective experience of different emotions. For instance, the core relational theme for pride is "achievement" which is different from that of sadness as "irrevocable loss". We argue that the complexity of inter-cultural communication often requires a more differentiated analysis of the situation, leading to a range of discrete emotions. Neeley et al. (2012) reveals a wide range of emotional experience under a language mandate ranging from "restricted and reduced" to "anxious and mistrust", although it does not explain the underlying processes for such diverse emotions.

Once felt, different emotions activate distinctive motivational goals to modify the protagonist's relationship with the situation. In line with this path-dependent feature, these goals are informed by the core appraisal theme that underlies emotional experience in the first place (Frijda et al., 1989). For instance, whereas anger arising from "other-blame" produces the goal to remove the harm, fear deriving from "danger" is associated with motive to "avoid". Signaling the most effective coping strategy in the evolution of past experience, emotive goals translate into dominant behavior responses that people are inclined to enact. During 
emotionally charged event like intercultural communication, the elicited action tendency can be so impulsive that people often find themselves "out of control" (Loewenstein, 1996) and unable to translate the acquired knowledge for the new behavior (Bird et al., 1999). This point is reflected in a number of IB studies that show a strong emotional impulse for the undesirable code-switching communication behavior, despite the individual's strong language skills (Hinds et al., 2014). Thus, the emotion-behavior pathway can extend our understanding of "what exactly is it about language that creates a problem" (Harzing \& Feely, 2008, p. 52).

\subsection{Cultural variation in emotions}

The cultural shaping of emotions has become a topic of substantial debate and importance (Manstead \& Fischer, 2002). Moving beyond the earlier universality-specificity dichotomy, numerous studies have discovered both biological innateness and cultural calibration in emotions (for a review see Mesquita \& Frijda, 1992). What is needed is a theoretical framework within which to explain both cultural similarity and differences in individual emotional reactions to the same situation (Ellsworth, 1994; Mesquita, 2001).

Appraisal theory meets this need. The central proposition concerning the core appraisal dimensions that constitutes discrete emotion is universal, but the appraisal focus varies culturally (Mesquita \& Ellsworth, 2001). Specifically, in many Western countries where individuals strive for independent selfhood, the habitual appraisal is primed towards personal pleasantness (Kitayama et al., 2000), self-serving attribution (Imada \& Ellsworth, 2011), and readiness to influence others (Tsai et al., 2007), thus giving rise to pervasive self-focused emotions (Eid \& Diener, 2001; Kitayama et al., 2006; Tsai et al., 2006). In contrast, in many Asian countries where interdependent selfhood is prevalent, the implicit fostered appraisal tendency is predisposed to intersubjective harmony, self-effacing attribution and willingness 
to adjust to others, leading to a "hyper-cognized" other-focused emotion with low activation (Niiya et al., 2006; Miyamoto \& Ma, 2011; Sims \& Tsai, 2015). For example, Imada and Ellsworth (2011) found that Americans tend to attribute success to their own ability and experience a strong feeling of pride and satisfaction. In contrast, Japanese attribute similar achievements to others or circumstances, and reported lucky or obligated feelings. Similarly, Kitayama et al. (1997) observed that while feeling good is often highlighted in the USA as a function of asserting individual ability, personality and opinions, shame is often promoted in Japan to motivate individuals to fit perfectly into social standards. These general principles can be applied to the intercultural communication process in MNEs.

To summarize, our literature review suggests that extant research on emotions in the micro-foundation of language standardization has not fully capitalized on the insights from the psychological literature on the human emotion. As a result, we still know little about the nature and function of emotion in relation to the MNE communication. Our study is set against this background in order to elucidate 1) the effect of common language on the emotional states experienced by employees from distinctive cultural backgrounds and 2) how language-induced emotions influence an individual's intercultural communication behavior. We address these questions in the context MNE knowledge transfer, which is characterized by a need for a corporate lingua franca to facilitate intercultural communication (Welch \& Welch, 2008), and intense language-induced emotions felt directly by the individual protagonists (Hinds et al., 2014). We now proceed to discuss the research methods of our study.

\section{Research Methods}

\subsection{Research Design}

This research employs a single qualitative case study that is premised on the 
interpretative paradigm (Welch et al., 2010). As our literature review shows, theoretical development of language-induced emotion in MNE in-house communication is still in its nascent stage. Qualitative research is particularly appropriate for theory building because it allows the researcher to identify the themes and patterns that emerge from thick description, provides a source of new hypotheses and constructs, and generates theoretical explanation closely grounded in the event being observed (Birkinshaw et al., 2011).

Meanwhile, our research questions are geared towards obtaining a holistic picture of why and how staff from different cultural backgrounds in the MNE feel about language standardization via English. Case study design is preferred when "how" or "why" questions are being posed, when the investigator has little control over events and when the focus is on a contemporary phenomenon within some real-life context (Yin, 1994, p.1). Finally, our interest in discrete emotional experiences in specific knowledge sharing events mandates single over multiple-case design. We can obtain a deeper and more contextualized account of what an individual feels, thinks and how he/she acts under a language mandate, both in terms of the number of factors studied and the sources of information obtained (Patton, 1980).

\subsection{Research setting}

In this study, we employed Fletcher and Plakoyiannaki (2011)'s multilevel approach because it offers a systematic method to narrow down sample choices for studying an embedded business phenomena. Level 1 describes the selection of country. Different from other emerging markets MNEs, MNEs from China have been especially active in using FDI to leverage external and internal knowledge and languages are the basic means of communication in organizations and the basis for knowledge creation (Welch \& Welch, 2008).

Level 2 discusses the selection of industrial sectors. This study focuses on China's 
software and I.T. service industry. The need to acquire advanced knowledge including the latest software product, market trends, and client information mandates an intense communication throughout a typical high-tech firm.

Level 3 refers to the selection of MNEs. Our case firm is an unsophisticated Chinese firm and it offers a rare opportunity to see a change of state of a firm going from being entirely nationally focused to being entirely international - and the shock of that process. Since this study investigates communication in MNE global operation, the case company must demonstrate a sufficient level of internationalization. The case company represents the largest China-based I.T. service provider with 19,971 billable professionals, the first company able to offer global clients end-to-end service in the most cost-effective way, with over 60 per cent its net revenue coming from foreign markets. The company's status as "the most internationallyoriented China-based IT vendors" has been confirmed by IAOP 2014 report, ranking it in the top 10 global outsourcing companies.

The competitive advantage of this company lies in its signature "hybrid service delivery mode" through which core components of I.T. task - designing, building, testing and maintaining software - were organized into overlapping modules and executed simultaneously by a team of I.T. professionals in different locations. Such a multi-sited delivery system can strike a balance between the client's expectation of customized end-to-end I.T. service and concerns for costs and information security.

Level 4 indicates the selection of MNE units. We chose 3 HQs in mainland China and 6 subsidiaries in US, Europe, and Australia because of their crucial role and high workflow interdependence in the hybrid service delivery. Except for the Spanish subsidiary, the unit language of HQs and foreign subsidiaries are the dominant languages of their respective countries: "Chinese" and "English" (Schomaker \& Zaheer, 2014). All of the Spain-based staff 
are fluent in English due to their functional role in I.T. language service which requires using English as universal code to support software programming in various linguistic contexts. As the Spanish unit is managed by Americans, the daily business communication within the unit was conducted in English.

Finally, Level 5 refers to selection of the sources of evidence, which is explained in the next section.

\subsection{Data collection}

Our initial research question was "How do MNE staff perceive English as a common corporate language?" The relevant literature was used as "pre-condition" before beginning empirical testing. Once the fieldwork started, we spent most of the time observing to prevent our preconceptions from hijacking the empirical data. Adopting a sort of "anything goes" attitude (Swedberg, 2012), we gradually got a better grip on the research participants, their daily activities and organizational context. In particular, we were impressed by the spontaneous emotional reactions when the research participants interacted with their foreign counterparts. Interestingly, just a few days before we were expected to exit the field, our conjectures about the relevance of emotion in intercultural communication were directly supported by the research participants. With a stronger relationship built over 3 months, some of them even helped us to reformulate the interview questions, clarify the difference between anticipated and actual emotions, and recommend potential contacts or units that we might find useful to explore this issue. All our experience resonates with Michailova et al.'s (2014, p.141) insights that "exiting provides the opportunity to explore again, but in a different situation, the dynamics of the researcher-researched relationship, how the research is co-constituted by the researcher and research participants and how they may co-theorize". 
After identifying emotions as more relevant phenomena, we developed a preliminary interpretation of a theoretical contribution to the existing international business literature. Accompanying this new direction was the adoption of psychological theories to explore language-induced emotion in detail. Then we started the second round of fieldwork in the same case company.

\subsubsection{Semi-structured Interviews}

Our primary source of data for this study consisted of semi-structured interviews. We considered them particularly appropriate to tap into the informants' emotions arising from language standardization and to provide a thick description of emotional impact while "preserving the actual meaning that actors ascribe to actions and settings" (Gephart, 2004, p. 455). Following a theoretical sampling approach (Corbin \& Strauss, 2008), we conducted 60 interviews with the individuals who were in frequent contact with foreign colleagues. In order to generate maximum variability, we selected respondents who varied in terms of age, tenure, hierarchical position, functional area and international experience. Our final sample included the HQ- and subsidiary-level employees representing ten nationalities. Tables 1 and 2 provide the background information on the interviewees.

Insert Table 1 about here

Insert Table 2 about here

An interview protocol with open-ended questions was designed in light of the literature 
review, initial fieldwork, and our own experience of working in the case company. While the exact order of questions varied in accordance with respondents' narrative, the interview protocol consisted of three sections. The first part contained initial demographic questions such as company tenure of the interviewee, his or her current and previous job details and cultural background. In particular, we asked our participants to assess their foreign language skills and their level of English competence. Against the Interagency Language Roundtable (ILR) scale, HQ staff rated their English below full professional proficiency whereas the self-reported fluency by the subsidiary staff was up to bilingual or native level. The second part focused on emotional aspects of language standardization in the context of cross-border knowledge transfer. Consistent with the psychological literature, emotion develops from an immediate appraisal of a specific event with more identifiable trigger and outcome. Unlike longer lasting "mood" or "feeling", emotion as intense coordinated response is more short-lived and episodic in order not to stretch the individual's resources (Frijda, 1993).

Following Durand (2016), we employed the critical incident technique to capture better and explicate different emotionally charged episodes induced by the English-only policy. Specifically, the participants were asked to describe critical knowledge sharing events with foreign colleagues, encouraging them to use episodic memories (Tulving, 2000), which generated a more valid experiential account of participant's cognitive, emotional and behavioral states (Robinson \& Clore, 2002). Our sample interview questions included: Can you recall a specific situation where you found it problematic or demanding to communicate information in English with your foreign colleagues? What sort of communication issues did you experience and how did they affect your attempt to exchange information? The critical incidents mentioned by the interviewees are summarized in Table 3 below. 
Insert Table 3 about here

We then continued the interview with more probing questions: In that particular situation, how did you feel about the mandate to communicate in English, and why did you feel so? We deliberately left any explicit request of naming the felt emotions to the end, by which time the participants were able to rekindle and describe emotional reactions spontaneously instead of using their general categorical knowledge of the emotion. As empirically demonstrated by Vuori and Huy (2016), managers relying on episodic memories recalled more specific explanations of "when" and "where" they had a particular emotion, rather than simply describing "what" that emotion was.

In this way, the emotional experience they reported had a more meaningful, enduring impact (e.g., getting furious with foreign colleagues when the interviewee was under time pressure to obtain a critical piece of knowledge), eliminating those less consequential, transient feelings that could be forgotten quickly or were too rare to form an accumulating pattern (e.g., getting annoyed with technical breakdown during the video conference). In the final part of the interview protocol, we sought to explore the emotional repercussions of English as lingua franca with typical questions such as "How does language-induced anger/frustration/shame impact the way you communicate and interact with foreign colleagues?" and "What do you do to alleviate the negative emotions, if any?" The average duration of the interviews was around 1 hour and they were conducted primarily on the workplace premises of the participants via face-to-face conversation (40), Skype (15) and telephone (5). All Chinese or English native speakers were interviewed in their mother tongue, partly due to the first author's Englishlanguage skills and Chinese nationality and partly to establish rapport to obtain more reliable information (Welch \& Piekkari, 2006). Five participants in European subsidiaries were interviewed in English because our small research team was unable to speak all their native 
languages fluently (i.e., Spanish, German, Finnish, Swedish) and the interviewees were used to speaking English as part of their daily work. We digitally audio-recorded all these interviews and transcribed them verbatim in their original language, after obtaining prior consent from the participants. All the interviews were digitally audio-recorded and transcribed, after obtaining prior consent from the participants.

\subsubsection{Participant Observation}

Observation was conducted along with the interviews. Following Werner and Schoepfle (1987), we first conducted a "descriptive observation" which included the unit's location, daily work practice, and notice board. This was to develop a contextual understanding of the business environment where the chosen units are embedded. It was followed by "focused observation" on inter-unit knowledge transfer as an act of intercultural communication including linguacultural discrepancy in language choice, communication style and contact building. For instance, sharing a large open-plan office with the employees from Corporate Marketing, Business Development and PGS team (Product Globalization Service), we often observed and listened to conversations among themselves or with their foreign colleagues.

Finally, there was "selective observation" on emotional reactions such as facial expressions, speaking tones, bodily gestures and spontaneous communicative behaviors when the informants were sharing information with their foreign colleagues. Following the argument for basic human emotion with universally recognizable expressive cues (Ekman, 1992), we used Roseman's (2011) emotional system model to code the expression of momentarily felt emotions such as brows lowered, loud voice, square mouth with behavioral tendency to hit for anger and brows raised, trembling voice, eyes wide open with a behavioral intention to run for fear. A brief interview was conducted with the participants after the observation, aiming to 
understand their different views, attitude, and expectation of the displayed emotions. For example, by observing eight bi-weekly cross-site teleconferences between China HQ and foreign subsidiaries, we noticed a striking difference of dominant emotional reactions towards communication barriers. This observation directed our inquiry to cultural influences on emotional experience, which was further clarified, discussed and explained through our subsequent interviews.

\subsubsection{Documents}

A wide range of documentary data were collected including annual reports, internal newsletters, new employee orientation, cooperate training and promotion criteria. The purpose of using documents was to verify, complement and elaborate on the emerging insights from the interviews and observations. With this focus in mind, we first selected and grouped the documents in terms of three broad topics: 1) the organizational context where intercultural knowledge communication is embedded, 2) language and culture issues in communication, 3) emotional responses to English as lingua franca. For instance, a chain of emails between a Chinese member of staff in corporate marketing and his American colleagues provided extra evidence of lingua-cultural difference in communication. A number of emotionally charged narratives from one staff forum contained the attitude, behavioral and even physical changes under certain emotional states that we were not able to observe directly. Then, following the qualitative position that documents are products of social interaction (Altheide, 1996), we read the selected documents in an interpretive manner, and made notes on the meaning, context or intension from which these materials were created (Mason, 2002). Finally, these notes were compared to the emerging themes derived from the interviews and observations to strengthen or broaden our understanding. For example, the note of "being open-minded" and "need to be 
assertive" from one communication training manual directed our attention to the way participants try to cope with emotional challenges in intercultural communication.

\subsection{Data analysis}

Our data analysis was guided by an iterative process of cycling among data, existing literature and emerging constructs until theoretical saturation was reached (Locke, 2001). An important link over multiple iterations is coding the phenomenon under the investigation (Corbin \& Strauss, 2008). Following Gioia et al.'s (2013) practice, our coding consisted of three steps. In the first step, during open coding, we read the transcripts multiple times to a) identify the occasions where our interviewees found it difficult to communicate when one party was not an English speaker, and b) to trace the perceived criticality, description and solution of these challenging situations (Chell, 1998). This discovery process resulted in a range of critical incidents from which we created nodes to analyze the emotional as well as cognitive aspect of intercultural communication in MNE context (Durand, 2016).

Then we focused on different meanings of these designated codes given our unique cross-lingual data source (Welch \& Piekkari, 2006). For example, we used Roseman's (2011) Emotion System as our organizing framework to deductively code discrete emotions. The framework offers a detailed appraisal dimensions and its corresponding phenomenological, expressive, behavioral and motivational cues that account for major discrete emotions in the given communicative encounter. As we went deeper to examine the meaning, attitude and enactment of those emotions across the employees with different social-cultural background, it generated the some emotional experiences that were not directly accounted for by Roseman's (2011) model. In this situation, we interpreted these data in the light of Lazarus's (1991) core relational themes for human emotions and Ellsworth \& Scherer's (2003) appraisal theory to 
make fine distinctions between certain emotions such as "anger" and "resentment". Table 4 shows how emotions were coded and inferred from our multiple sources of data.

Insert Table 4 about here

In the second step, during selective coding, we determined the common properties of those codes and made them more thematically abstract. To perform these steps, we sought similarities and differences among these codes via different ways of data comparison and grouped them into broader categories. For instance, with regard to the communication barriers associated with language standardization, we group "visible uneven English proficiency" and “invisible communication conventions". Similarly, the codes "individual hierarchical position in the organization", "personal contacts" and "international experience" are aggregated into "cognitive ability" to regulate the negative emotions towards language asymmetry. In the final stage of analysis, we refined and juxtaposed the recurring ideas against the existing literature on language standardization, emotions and intercultural communication, thus proceeding from a data-driven to a theory-guided analysis (Gioia et al., 2013).

While coding was predominantly conducted by one of the co-authors, the emerging themes had been discussed among all the co-authors during the entire process of data analysis. Because our interest in this study was in emotional experience of intercultural communication in the MNE, we decided to ground our analysis primarily in the interview transcripts with additional support from the observation and archive data ${ }^{1}$. Our cultural and language similarity with the participants gave us an in-group advantage to explore the emotional display and

\footnotetext{
${ }^{1}$ Our transcripts were checked by two fluent Chinese and English speakers with professional knowledge of international business and they confirmed that our translation was accurate and consistent.
} 
enactment in intercultural and cross-lingual MNE context. Our team consisted of a Chinese native speaker who was also fluent in English, which facilitated the interpretation of data from the Chinese speaking respondents. The remaining team members were two native English speakers (British) and one Polish researcher, who was fluent in English. This helped our interpretation of the non-Chinese responses. The Polish team member is also a professional translator and interpreter (English-Polish and Polish-English), which gave us a mental model of what it is like to be using more than one language and understanding of language switching and the emotional responses it generates.

\section{Results}

\subsection{Language difference}

Given that the majority of I.T. outsourcing customers come from the English-speaking countries, English proficiency plays a pivotal role in the assessment of the vendors, particularly those from emerging countries (Oshri et al., 2015). Accordingly, the company established English as the formal working language for international projects. In the view of the company's top managers, using English as lingua franca facilitated information exchange between globally distributed workers and helped to build a binding corporate culture:

"If the company wants to be a genuinely global I.T. service provider, English has to be the common language for international project teams to exchange the ideas with each other and to respond to our clients in different countries" (\#12 American).

This, however, was not without problems:

"I have witnessed many talented foreign software developers or sales people leaving the company. One important reason is that they found it difficult to get integrated in the corporate 
culture because most of time we [HQ staff] communicate with each other in Chinese" (\#21 Chinese).

Our data further suggest that the introduction of English was not a panacea for effective intercultural communication. On the contrary, it generated an uneven proficiency in the lingua franca between native and non-native English speakers (Marschan-Piekkari et al., 1999a). More specifically, most subsidiary staff were native English-speakers or bilinguals with a professional English proficiency. By default, English became the daily language spoken in the workplace. In contrast, although English as corporate language was a part of the training, most HQ staff feel it more natural to discuss work-related issues in Chinese. Thus, the English-only policy was perceived by Chinese personnel as a "mental handicap" for the ideas which could be otherwise easily articulated in their mother tongue. Given the extra effort to find the appropriate words, most Chinese informants felt "stressed", "anxious" and "exhausted" in using English for both verbal and written communication. As described by one Chinese project leader:

"A two-page standardized project briefing that only takes me 2 to 3 hours to prepare in Chinese could cost me a whole day if the document had been produced in English. I have to constantly check and correct the words that might cause misunderstandings for the foreign onshore team. Naturally, this makes you lose interest to get to know these overseas colleagues at a more personal level." (\#2, Chinese).

Echoing the experience of the non-English speakers, subsidiary personnel believed that overall English proficiency in HQ did not reach the level which would enable effective crosssite collaboration. As one middle manager commented:

"Quite often, you do not understand what they are trying to say even after a 1-hour meeting" (\#19, European). 
Other foreign informants reported that the objectives of team meetings were unduly disrupted by clarifying or explaining technical terms for the Chinese teams. Recalling a recent audioconference with the HQ on the new Big Data project, one American manager said:

"When the topic involved technical jargon which did not have the equivalent word in Chinese, the discussion became very difficult. I had to stop the original meeting agenda and explain every single technical term in English painstakingly. As soon as I finished that difficult meeting, I instantly got 5 or 6 emails asking about the technical terms I had explained before” (\#12, American).

Although some Chinese managers were fluent in English, the need to explain or request contextual information on the project forced them to use "fancy words phrased in long sentences", which was perceived as "completely unnecessary" by native speakers. This point was well illustrated by one native English speaker:

"In the US, we believe 'less is more'. People at work will use simple words to frame their questions or statements. [...] Based on my observation, our Chinese colleagues seem to like writing long emails with fancy words." (\#15 American).

However, if not structured well, this excessive verbosity became cognitively taxing for the English native-speakers to capture the core message. One Australian middle manager recounted what he said was a frequent occurrence:

"It took me quite a long time to read through an email from HQ and I eventually realized that it was simply a meeting request. The funny thing is that I still can't figure out what I need to do or to prepare for that meeting" (\#1 Australian).

Underneath the visible uneven English proficiency was the disparity of invisible communication conventions in different speech communities (Gumperz \& Gumperz, 1996). Underlying English as the standardized I.T. language is a "fast" "direct" and "clear" 
communication code to facilitate information exchange (Zaidman \& Brock, 2009). Many native English speakers contended that the success of their main international competitors (Indian outsourcing companies) was due to their superior English communication skills.

Behind the façade of Chinese there was a concealed communication code characterized by "face saving" and "face giving" contingent on different participants in the knowledge sharing process (Buckley et al., 2006). For instance, we often observed that Chinese staff spoke to their peers with a friendly, informal and agreeable tone, and quickly switched to a more deferential, formal and humble style once their supervisors joined in the discussion.

The tacit rules of language used by native and non-native English speakers lead to the perceived incompatibility in collaboration. The subsidiary personnel saw their Chinese counterparts as "less open to sharing critical information" or "hiding behind their words". The HQ staff, on the other hand, thought foreign team members were "abrupt", "intrusive" and "antagonistic" in project meetings. Not surprisingly, our data confirm the view that although a shared language is being used to facilitate information exchange, people continue to use diverse interpretive frameworks derived from their respective language systems (Henderson, 2005).

\subsection{The emotional experiences with English as lingua franca}

From a sociolinguistic perspective, individuals from one language community often assume certain language and speech forms as universal. When normative linguistic expectations are challenged in intercultural communication, this dissonance often triggers strong negative emotions in multicultural teams (Von Glinow et al., 2004). Confirming this perspective, our data show that non-native speakers felt "stressed" when experiencing difficulty in expressing their ideas precisely in a foreign language or attempting to adopt a different communication practice. As stated by a senior Chinese project leader: 
"In here (HQ), when I give an instruction to my team member, I will normally say 'do this or do that', and they are very happy to follow my order. However, when I communicate the same message to foreign staff, I have to choose the expression such as 'we are expecting you do this or do that'. As a manager, it does make you feel you are begging your subordinates to work" (\#10, Chinese).

Similarly, when switching from a native English-speaking context to "international English" context, subsidiary personnel had to deliberately override their habitual way of using English in terms of vocabulary, pace of speech and accent. Such discursive changes often evoked intense feelings described as "uncomfortable", "awkward" and "unnatural". One USbased informant described those feelings in the following way:

"It feels quite unnatural to use different accents, speed and style of speaking in the teleconference with the Chinese HQ. You feel that you are speaking 'against yourself' in a way. It is particularly awkward in the meetings with my American colleagues or clients who know me very well” (\#8, American).

Rather than an aggregate affective state such as "foreign language anxiety" (e.g., Aichhorn \& Puck, 2007), our data reveal more heterogeneous emotional experiences based on the employees' subjective assessment of language standardization in an interpersonal, crosscultural context of MNE communication.

\subsection{Language-induced emotions felt by the subsidiary personnel}

In line with appraisal theory of emotion (Smith \& Ellsworth, 1985), we identified a number of dominant emotions felt by the HQ and subsidiary staff respectively, described in the following sections. 


\subsubsection{Anger}

In an attempt to ease foreign language anxiety, non-native English speakers often reverted to their mother tongue in cross-lingual communication or code-switching (Auer, 2000). We observed that code-switching occurred frequently in the meetings where the complexity of projects or technical subjects drove the HQ staff to consult with their co-workers in Chinese.

As the Chinese delivery team usually outnumbered the foreign on-site team, the meetings tended to turn into a prolonged Chinese-language discussion. Using the analogy of Pandora's box, all the subsidiary personnel we interviewed vividly recalled the incidents in which the rampant code-switching excluded them from important information exchanges:

"The meetings usually start in English, but once the Chinese start to discuss a topic among themselves, it is just like opening a Pandora's Box, their conversation can go out of control and turn the whole meeting into a Chinese talk-show" (\#21 European).

In response, anger was typically experienced by the native English speakers at the managerial level. A distinctive feature of anger is a perceived wrongdoing where blame goes to other people (Lerner \& Tiedens, 2006). One top American manager described his fury when the Chinese managers switched to their native language without warning:

"I sat in one project meeting that in the beginning was conducted in English. Then a few Chinese words popped up and the meeting suddenly turned into an entire Chinese conversation. When I insisted on an explanation, I was only given less than 5 or 6 sentences to cover their 30-min talk. That was very rude as they clearly knew the English was the language of that meeting” (\#16, American).

Other native English speakers became more upset by the lack of genuine intention or willingness to address the negative code-switching from the Chinese HQ side. One US-based manager explained it with a fast, rising and forceful tone: 
"I wrote to one Chinese project manager, asking for a case study. The email was short and written using plain English words. Then the email was forwarded to other Chinese project managers and it became a chain of Chinese correspondence back and forth. Nobody was bothered to translate the content for me or even ask for my view in English, the language the Chinese HQ was trying to promote” (\#14, American).

In sum, the angry informants appraised language barriers as the direct result of "unacceptable" code-switching behavior by the Chinese staff who did not follow or implement the English-only policy. As the anger is accompanied by a strong coping potential to rectify the wrongdoing (Gooty, 2009), the angry subsidiary managers tended to address codeswitching aggressively by designating one English-speaking Chinese manager as a translator, demanding a full meeting report in English or terminating the communication with those who did not stick to the corporate language policy.

\subsubsection{Resentment}

Described as a repressed but the coldest form of anger (Feather \& Sherman, 2002), resentment is a negative emotion in which the individual has no other option but to endure unfair treatment. Resentment was mainly felt by the subsidiary staff at the operational level when they were unable to enforce the English-only policy due to their newcomer status or situational constraints. In order to acquire the critical information in English, they had to "show respect and seek favors" from their Chinese counterparts who constantly disregarded the company's language mandate (\#4 Australian). The perception that the deference HQ staff reaped in communication came at the cost professional value on authenticity and independence provides the basis for resentment (Feather \& Sherman, 2002). One Australian marketing analyst who joined the company less than a year ago described his resentment in the following words: 
"To be honest, since my role is in sales, I can only focus on the things that the Chinese HQ are suggesting. [...] So far I have not got enough information from the Corporate Marketing team in China. So when they speak to each other in Chinese, I have to put on a smiling face and to ask politely for their explanation in English” (\#4, Australian).

The feeling of undeserved submission was echoed by another US-based project manager whose team primarily relied on the work supplied by the Chinese HQ. Given this dependency, she had to bottle up the anger induced by the "rude" code-switching:

"Every time when I need information, I have to ask them [HQ staff] a favor to speak or write in English. Well, some Chinese colleagues told me about the importance of developing a 'thick skin' in the Chinese culture. Yes, it helps partially. But they do not understand that I am not Chinese and why would I have to develop the Chinese 'thick skin' to beg them to use the language that they themselves require to use" (\#10, American).

This Chinese code switching did not induce anger but generated resentment that lead to the creation of in-groups and out-groups, which became persistent and inimical to successful knowledge transfer. One native English speaker, who had only just taken up the position of marketing director in Europe explained:

"My nationality hurts because I am culturally different. No matter how good their English is, they still feel more safe or comfortable interacting with each other in Chinese. There are still lots of people in HQ who I can't really talk to. They are in senior positions with lots of critical information. But they prefer speaking only Chinese. That is definitely hurtful" (\#21, European).

\subsubsection{Frustration}

Frustration is an unpleasant feeling triggered by failing at something for which success is expected. Although someone is held responsible for the consequences, the exact cause of the failure is less clear (Smith \& Ellsworth, 1985). According to our data, frustration occurred in 
the situations where knowledge exchange was impaired by the disparity of the communication code obscured by English as lingua franca. For example, one European manager talked about his frustration with the ambiguity of the Chinese delivery team's response in project planning: "When suggesting a project schedule, we often get a vague response which I cannot tell is a 'YES' or a 'NO'. We might think of it as a 'YES' as none of the Chinese team members opposed the proposal but then the Chinese side does not follow the agreed plan. They tell us they interpreted the original timetable in a totally different way. That is quite frustrating as it causes the issues we are not prepared to deal with” (\#20 European).

Another US-based project leader added that the Chinese staff were reluctant to communicate problems in good time. His account of one project was filled with frustration and disappointment:

"There were a few bugs in the testing system, but they did not let our onsite-team or customer representative know about them. Then 3 days before the delivery date, and when they realized they could not sort out the problem themselves, they approached us and said 'we have got a problem'. So we had no choice but to re-run the testing system and to revise the entire program. Although the project was completed in the end, nobody was happy. And our project manager told me directly he did not want to work with that Chinese delivery team any more" (\#12 American).

As the "other-blame" emotion, frustration exacerbated negative evaluations of the Chinese team's competence and motivation in cross-lingual communication. Several informants considered their Chinese counterparts quite "messy" in fixing a project timetable (\#5 Australian) or possibly "too lazy" to deliver the allocated work against a challenging but agreed deadline (\#10 American). In addition, given the disparity of communication conventions that were difficult to detect and to overcome, the frustrated native speakers tended to develop intense feelings of "helplessness" after repeated communication breakdowns. In 
such an emotional state, individuals believe attribution of responsibility is less relevant as nothing can be done to repair communication (Frijda, 1986). Thus, over time, the frustrated subsidiary personnel ceased their communicative effort and passively engaged in collaboration. This is illustrated in the following quotation:

"I repeated many times, in simple English, that I prefer them [the Chinese delivery teams] to bring any problems to my attention rather than to try to solve them on their own. Unless you remind them 24/7, they still like to keep the problems to themselves” (\#20 European).

Our data further suggest that language differences thwarted the subsidiary personnel's psychological need for individual competence and autonomy in the MNE knowledge transfer. In our interviews, foreign managers at all levels often mentioned that the case company provided untapped potential to utilize their technical and managerial expertise. For example, one top Australian project manager, who had worked for many prestigious I.T. companies, emphasized the impact he could make on the emerging multinational:

"My decision is based on the potential for business development. [...] For me, this company has 23,000 employees as well as fantastic clients. I would like to see how I can get my hands on these capabilities, and help this company grow not just in Australia, but as a truly global company” (\#3 Australian).

The emphasis on "competence" and "control" mutually reinforced the professional image of an "I.T. consultant" as a self-determining, ambitious, change-driven agent. Rather than leaving because of the feeling of losing power (e.g., Gupta \& Govindarajan, 2000), knowledge transfer became the most prominent way for the subsidiary staff to gain "personal visibility" and "influence" in the Chinese multinational. Once the objective of individual accomplishment was threatened by the language barrier in the MNE knowledge transfer process, intense negative emotions (e.g., anger, resentment, frustration and sadness) naturally occurred, and provided those self-reliant I.T. professionals with the adaptive strategy to assess 
and address their communication issues. Our findings are consistent with the argument that people from "non-conforming-to-group-norms" cultures tend to experience ego-focused emotions due to the independent self-construal (Markus \& Kitayama, 1991).

\subsection{Language-induced emotions felt by HQ personnel}

\subsubsection{Shame}

Shame arises in the situation in which an individual has done something wrong (Smith \& Ellsworth, 1985) or failed to display a specific behavior in a social context (Tangney, 1992). The distinctive feature of shame is that "an objectionable behavior is seen as reflecting, more generally, a defective, objectionable self". With this painful self-scrutiny, shamed people feel a sense of "shrinking", "being small" and of "being ridiculed" by an internalized observing “other" (Tangey et al., 1996, p.1257).

Shame was often experienced by the managers who are unable to express their ideas in English, particularly in verbal communication such as a video conference call or a project presentation. Feelings of shame were described by one project manager when recalling a presentation he made for account managers and clients in the US.

"When I began to introduce my team in English, I suddenly felt my tongue was held up and I couldn't remember the things I prepared. I felt humiliated when my team were looking at me on my side and the silence I got from the American side. Then I managed to finish the presentation but I could not remember what I had said." (\#11, Chinese).

Another manager highlighted the feeling of shame when she failed to live up to the expectations from the team in cross-lingual business communication:

"I was so nervous that I could not speak properly to a group of the American sales managers about the projects we have done. I felt I suddenly lost my charm and became an extremely shy 
person instead of a confident, articulated and likable professional who can represent our team. Ifelt I had disappointed my team as well as myself” (\#26 Chinese).

It can be inferred from the above quotes that not speaking good English was perceived by the Chinese staff as a personal flaw and demonstrated becoming incapable and unlikable in the eyes of their colleagues.

The tendency for such harsh self-criticism also impacted on Chinese staff who could speak English well:

"In school and at the university, we were told by the teachers to learn correct grammar first in order to write or to speak proper English. It is the same in the office where you are expected to speak or to write perfect English when communicating with the native speakers. Otherwise, you will become the laughing stock or ridiculed by other colleagues.” (\#25, Chinese).

Interestingly, when asked, there was no shared agreement on the nature of "perfect English" that a competent and sociable employee was expected to demonstrate. While some emphasized "grammar, words, structure", others mentioned the "style, accent and intonation". A general view was that their language ability would be implicitly or publicly judged by others. In line with Kitayama et al. (1997, p.1254), the fuzzy attributes of perfect English indicate "a practical impossibility" to achieve the ideal image of a good English-speaker, which in turn reinforces the tendency for self-criticism and feelings of shame.

Given its painful and harsh rejection of one's core self, shame leads to the desire to hide away from the humiliating experience (Tangney et al., 1996). The Chinese employees who felt shameful about their English language skills tended to avoid communicating with the native English speakers and at the same time they inflicted a self-directed anger for not putting adequate efforts into learning English. 
However, the employees who experienced shame often exaggerated the importance of language proficiency in knowledge exchange at the expense of their professional expertise. As one experienced Chinese project manager stated:

"If I know I cannot use very good English to express my view on certain technical issues, I will not comment on it even if I perfectly know where the problem is. The poor English only creates more confusion and misunderstandings. So the safest way is not to speak at all" (\#1 Chinese). Thus, the experience of shame can better explain why the inferior proficiency in the corporate lingua franca might distort self-evaluation of professional expertise in knowledge transfer as reported in the previous literature (e.g., Vaara et al., 2005; Tenzer \& Pudelko, 2017).

\subsubsection{Indebtedness}

Indebtedness is defined as "a state of obligation to repay another", which arises from norm of reciprocity (Greenberg, 1980, p.4). It is associated with negative feelings such as "discomfort", "uneasiness" and "upset". When the expected return is perceived to be high, unpleasant feeling of indebtedness becomes more intense (Watkins et al., 2006).

According to our data, indebtedness occured mainly during written communication where the Chinese staff felt that they could not supply the same amount of information (i.e., case studies, white paper, sales reports, competitor analysis) that they requested from the subsidiary. A lack of the necessary English skills to codify tacit knowledge in English was perceived as the main reason for this asymmetry. A comment from one senior manager who has been working in the Chinese HQ for 16 years captures this point:

"Most of our executives used to be top managers of the successful MNEs such as HP or Microsoft and they clearly know about the benefits of knowledge management system for I.T. service companies. The issue is who is able to translate and organize our capabilities in the Chinese HQ into a knowledge system in the language and style our foreign colleagues find 
useful" (\#27, Chinese).

Echoing this view, most Chinese informants found "getting the story out of one's head" already difficult in itself and it was even more difficult if it had to be done in a foreign language. As knowledge transfer assumed some level of reciprocity, the obligation to repay a similar quantity and quality of information seemed too much for the Chinese employees, and it lead to unpleasant feeling of indebtedness. For instance, one Chinese manager talked about the felt discomfort in asking for more sales supporting documents before she could repay the favor:

"I contacted Ana in Europe asking for a case study on machine translation for Microsoft MSN project. She was very nice and provided me with the relevant material very quickly. One month later, she kindly helped me with another case study of Microsoft Bing Project. However, just a few weeks ago, I needed some materials from her team again. I really felt discomfort to bother her again as I have not helped her with any documents. I felt I owed too much debt to her" (\#10 Chinese).

As an integral part of "face giving and saving" in interpersonal relationships (Yang, 1994), the expectation of reciprocity was particularly high for the Chinese employees. In the words of the Chinese informants, failure to repay one's help would be labeled as "Bu Yao Lian" ("I don't care about one's and other's face") or "Mei Xin Gang” ("black heart"). As a result, a narrow "tit-for-tat" mentality associated with indebtedness constrained the Chinese staff's options on with whom they could communicate and when. As stated by one of the Chinese informants:

"I will not actively ask for information or other resources from those foreign colleagues unless I know I can do the same for them in a similar situation" (\#9 Chinese).

This is in accordance with Watkins et al. (2009) who found that the emotion of indebtedness tends to reduce uncomfortable obligations by avoiding more help in the future. Interestingly, some of the subsidiary staff found the term "indebtedness" difficult to understand. While a few 
top foreign managers were familiar with this emotion, they believed that this feeling was unnecessary in business communication, even if it involved good intentions to show consideration and to accept obligations.

Our data further reveal that language difference thwarted the HQ personnel's psychological need for relatedness to others from the knowledge transfer. Many Chinese informants believed that knowledge exchange also involved genuine care, long-term relationship building, and identification with a group. This is in line with Chua et al.'s (2009, p. 504) observation that the Chinese employees are more likely to "mix social-emotional concerns with instrumental concerns in the workplace interaction". The focus on relatedness also echoed the professional identity of "team-driven, modest, supportive I.T. outsourcing programmer". Knowledge sharing was perceived to be learning process where individual goals were fulfilled via social interaction and relations with other group members. As the language barrier caused difficulties in these team workers' attempt to build connections and to be understood by others, intense negative emotions such as "shame" and "indebtedness" were naturally evoked.

\subsection{The impact of cultural predisposition on emotions generated in intercultural}

\section{communication.}

In the light of the above discussion we argue that culture affects the emotions generated in intercultural communication through cultural predisposition of the protagonists. This is in line with the central proposition concerning the core appraisal dimensions that what constitutes discrete emotion is universal, but the appraisal focus varies culturally (Mesquita \& Ellsworth, 2001). The cultural predisposition will affect the nature of psychological contract that individuals will have in the process of language standardization, as exemplified by the contrast between the "conforming-to-group-norms" cultures as represented by the Chinese and the 
"non-conforming-to-group-norms" cultures as represented by the native English speakers.

The Chinese employees treated a psychological contract with their peer group as more important than the one with the firm, and therefore they did not adhere to the requirement of speaking English. This is in line with Peng et al. (2016) who found that Chinese emotional reaction towards a violation of a psychological contract is more spontaneously aroused from their specific interactions with their partners rather than based on calculative judgement of their exchange relationship with the organization. This is due to their cultural emphasis on the self as a social interdependent entity. As demonstrated in the previous section, Chinese respondents tended to display "face saving" and "face giving" behaviors and they felt shame if these were disturbed. The "indebtedness" is a good example of how individual's inability to employ the lingua franca interfered with his or her ability to reciprocate to the other party. The indebtedness is something that is specific to the Chinese culture and in this example, it directly interfered with intercultural communication process as the protagonists felt the shame of their poor English proficiency, which prevented them from reciprocating the knowledge. They also faced difficulty in expressing their ideas relating to hierarchy in English. For example, a Chinese project leader had to adapt their communication style to a more consultative one while speaking to non-Chinese colleagues, which would not be the case while communicating with their Chinese subordinates. Our findings are consistent with the argument that people from "conforming-to-group-norms" cultures tend to experience other-focused emotions due to the inter-dependent self-construal (Markus \& Kitayama, 1991). The implication of this that their appraisal tendency would be predisposed to intersubjective harmony, self-effacing attribution and willingness to adjust to others, leading to a "hyper-cognized" other-focused emotion with low activation (Niiya et al., 2006; Miyamoto \& Ma, 2011; Sims \& Tsai, 2015).

By contrast people from "non-conforming-to-group-norms" cultures would expect to the psychological contract between the employees and the firm to be adhered to and for 
everyone in the company to use English as formally agreed. They would strive for independent selfhood and their habitual appraisal would be primed towards personal pleasantness (Kitayama et al., 2000), self-serving attribution (Imada \& Ellsworth, 2011), and readiness to influence others (Tsai et al., 2007), thus giving rise to pervasive self-focused emotions (Eid \& Diener, 2001; Kitayama et al., 2006; Tsai et al., 2006). This was evident in the statements from subsidiary staff who felt resentment towards the "in-group" and "out-group" attitude of Chinese staff who tended to speak Chinese amongst themselves and thus to exclude their nonChinese speaking colleagues. The non-Chinese staff also expressed their frustration with their Chinese colleagues for not sharing problems as they have arisen, but instead hiding them until the very last moment. This demonstrates the "non-conforming-to-group-norms" cultures psychological need for individual competence and autonomy.

5.6. The role of individual cognitive capability in responding to negative language-induced emotions.

In line with Gross \& Thompson (2007), we define cognitive capability as individual skills to reappraise the cognitive meaning of a specific intercultural communication event. The purpose is to attain a more positive emotional state as a basis towards achieving the strategic objectives of the communication. Our data suggest that this cognitive capability derived from "hierarchical position", "personal connection" and "international experience". These three experiential assets enhanced self-perceived efficacy to attend, understand and alter the emotionally burdensome incidents triggered by language mandate (Elfenbein, 2007; Loewenstein, 2007). We identified the cognitive capabilities of interest, compassion and challenge as those utilized by MNE employees to facilitate intercultural communication.

\subsubsection{Interest}


Interest is a psychological state of engaging with a particular situation that is appraised as unfamiliar, complex but comprehensible with focused attention (Silvia, 2005). Through repeated exposure to the events with similar attributes, "situational interest" could develop as an enduring trait-like epistemic curiosity with certain activities or "personal interest", stimulating more engagement with the object of interest (Hidi \& Renninger, 2006). Acting as a cognitive defense to anxious feelings towards what is not familiar (Silvia, 2005), interest helped our interviewees to experience communication disruptions caused by a common language as less stressful and more intriguing to explore. When asked about the experience of working with the Chinese colleagues, one top European manager highlighted the value of language and cultural diversity:

"Generally speaking, I am relatively curious. I think it is quite interesting to talk to people from different countries with different backgrounds. I do not see working with Chinese managers as a problem but rather as an opportunity to get to know a different culture and language” (\#20 European).

With organizational power afforded by seniority, this top European manager has organized a number of formal communication training sessions based on the real examples of intercultural, cross-lingual interaction that he and his Chinese counterparts have collected. While being asked about his own strategies, he explained the situated communication style: "When interacting with my Chinese colleagues, I am quite diplomatic most of the time, I try to bring up different opinions and to list pros and cons. [...] But when it comes to key issues such as agreed deadlines, project blueprint and basic quality standards, I am very clear, specific and straightforward.... My communication style is not rigid but more in line with the nature of the task" (\#20 European).

\subsubsection{Compassion}


Compassion "arises in witnessing another's suffering and that motivates a subsequent desire to help" (Lerner et al., 2010, p.351). Thus, compassion is often described as a "caretaking" social intuition (Oveis et al., 2010). Compassion can be inferred from the statement of one US-based manager:

"When I set up conference call with the managers and engineers in a delivery team, I got the feeling that they were struggling to express themselves in English. I would say OK, you can speak Chinese. I was not offended. But once you talk in Chinese, let me know the content of your discussion as much as you can” (\#12 American).

The negative tension caused by the potential code switching was reduced by the manager taking the perspective of non-native English speakers which helped to transform anger into empathy. Tolerance and adaptation displayed by the sympathetic native speakers were particularly appreciated by the Chinese staff with low English fluency who, in turn, worked hard to maintain a positive communication experience with their foreign colleagues. In speaking about his American colleagues, a Chinese informant remarked:

"Although English is an official working language for cross-unit interaction, 95 per cent of staff in the company are the Chinese who prefer talking Chinese with each other. When you see the American colleagues are trying their best to share their ideas by putting us at ease with [speaking] English, I think we should practice English as much as we can, and show our intention to involve them in the company communications" (\#18 Chinese).

Given that compassion often entails mutual perspective-taking, our data suggest personal connections tended to promote empathic intercultural communication (Tsai \& Ghoshal, 1998). As explained by many of our interviewees, the trust built with their distant co-workers over time created a safe atmosphere where low- and high-fluency English speakers could talk about and understand each other's emotions without any fear or embarrassment. This is in line with the previous empirical research demonstrating the cognitive as well as emotional value of social 
interdependency in regulating individual emotions (Rime, 2009). One European manager, for instance, noted:

"Sherry Wu or Victory Wang is my go-to-guy when I need information on how the Chinese delivery team gets on with the work. As our relationship is getting stronger, we begin to share our feelings as well as thoughts about other team member's feelings towards cross-unit collaboration under the English-only policy. Now, they are my eyes in China to see how the Chinese side actually feels and thinks when communicating with us. And I become their eyes in Spain” (\#18, European).

\subsubsection{Challenge}

As in case of "shame", HQ staff who experienced "challenge" also reported some embarrassing language-related situations - such as referring to a foreign male colleague as a "she", using too many "thanks" in an email and being "too nervous to speak out". However, they did not perceive these deficiencies as involving deep-seated flaws to self and to an ideal external sanction. Instead, their evaluation was more specific to knowledge sharing and more personally tailored, thus distracting their attention away from the anxiety of using perfect English. Consider the following statement:

"For me, the ultimate purpose of writing an email in English is to get the message across. I would not worry too much if the words are elegant or grammar is absolutely right. However, before I send an email, I will make sure it has no spelling errors and that it can be easily understood" (\#3 Chinese).

Most of these interviewees had visited the host countries and believed that native English speakers were more forgiving when English is spoken by non-natives:

"My one-year study in the UK taught me that native English speaker[s] can understand what 
I want to express even [when] I may struggle with some words or make mistakes with grammar. To some extent, they are more tolerant than some non-native speakers who tend to pick up or get confused by minor errors" (\#7 Chinese).

Based on the above discussions, the Chinese informants who reported challenge were more task-focused in the context of using English for knowledge sharing. Thus they tended to reframe their failure to speak perfect English as a mistake from which they could learn. Such a challenge motivates staff to spend time and effort to learn language skills for more effective knowledge sharing. Based on the above findings, we argue that the relationship between cultural predisposition and the efficacy of intercultural communication is mediated by the individual's cognitive capability.

\subsection{Emotional influence on individual communication behavior}

Emotions, even the negative ones, inform individuals of impending problems or opportunities (Ekman, 1992), allow flexibility in response to interpretation of an event and choice of behavior (Scherer, 1984), and provide heuristics to regulate an individual's relationship with their social environment (Keltner \& Haidt, 1999). However, few empirical studies have investigated the consequences of emotions on the communication behavior of MNE staff (Aichhorn \& Puck, 2017). The analysis of our qualitative data have revealed that emotions provide individuals with a shortcut to address language barriers in a way that is consistent with the adaptive theme of experienced emotions. This heuristic becomes more important for the individuals to make informed decisions and judgments arising from the uncertainty of intercultural communications (Brannen, 2004). From the company's point of view, the emotions, particularly the negative ones, appear be "irrational" as they might discount the value of transferred information (Anger), breed suspicion towards a foreign colleague (Resentment) and amplify the perceived threat from a cross-border collaboration (Isolation). 
They are fundamentally rational for the individuals who address language barriers in relation to their own goals, preferences and resources.

Given these relational characteristics, emotions entail stronger motivational forces and thus explain the heterogeneity of individual intercultural communication behavior better than cognitive feature such as absorptive capacity (Cohen \& Levinthal, 1990), tolerance for ambiguity (Szulanski, 1996) or problem-solving style (Bhagat et al., 2002). For example, although both sides acknowledged the hidden language barrier with English as lingua franca, managers who experienced interest tended to perceive language difference as an opportunity in contrast to those resentful colleagues who perceived language as a problem which could not be solved. This finding confirms the argument that emotion is always "a response to meaning" and that cognition acts as a precursor to emotional response (Lazarus, 1991, p. 824). We therefore argue that an individual's emotions mediate the relationship between language standardization and the outcomes of intercultural communication.

\subsection{The intermediating role of emotions in intercultural communication.}

In this paper we bring together the psychological theory of emotion and the cultural variation of emotional experience literatures to explain the role of emotions in intercultural communication processes. We argue that emotion plays an intermediating role in that process and that it is culturally rather than individually embedded. Integrating these two strands of literature enables us to identify two types of effects in intercultural communication. These are: First order effects which arise from the individual protagonist's cultural predisposition to particular emotions (cultural variation of emotional experience) and second order effects which are interactive effects as protagonists respond to the specific behavior in the "other" culture (the psychological theory of emotions). Based on the previous literature and the findings of 
our qualitative study, we therefore include emotion as an intermediary role in the process of intercultural communication as presented in Figure 2 below.

Insert Figure 2 about here

Our findings are based on an interpretive research paradigm that there is no unique social reality which can be objectively established. Cultural predisposition and the experiences of the protagonists must be studied in order to understand and reconcile the subjective interpretations of the protagonists on both sides in intercultural communication. As demonstrated by Fiske et al. (1997), cultural meanings complement and inform basic psychological processes, which in turn generate and reinforce these specific cultural meanings and practices. Our findings accord with this approach while demonstrating the divergent subjective interpretations of the two sides of intercultural communication. Our empirical data show that emotions are created on both sides (i.e., native and non-native English speakers) in the process of language standardization and we interpret this phenomenon according to the theory building mission of this paper, summarized within our framework.

\section{Discussion and conclusions}

Our study contributes to theory by resolving the conflicting findings in the existing empirical literature which argues that language standardization either facilitates or inhibits effective intercultural business communication. We provide a framework within which intercultural business communication takes place when language is standardized. We argue that emotions are generated not only on the side of non-native English speakers but also on the 
side of native English speakers. Our study indicates that in some circumstances language standardization may generate more barriers than it removes in both the short and long run. In the short run, i.e. a specific instance of intercultural communication may be impeded by language standardization. In the long run, this may damage the willingness of the protagonists to share information.

While previous studies have highlighted the role of emotions in changing individual communication behavior (Aichhorn \& Puck, 2017), the nature and the function of these emotions have not been fully explained. We argue that emotions play an important intermediating role in intercultural communication processes. We integrate the psychological theory of emotion and cultural variation of emotional experience literature and are able to explain individual emotional responses to English as a corporate lingua franca within the MNE knowledge transfer which we treat as an act of intercultural communication (research question 1).

We argue that language standardization in a firm triggers emotional responses which can be analyzed as playing an intermediary role between the act of standardizing language and its effects on achieving organizational goals, reducing costs and building communities. We further argue that these emotional responses are culturally embedded as they are both culturally predisposed as well as a response to the specific behavior in the other culture (research question 2). This accounts for the previously conflicting findings in the literature on language standardization.

Our research shows that emotions are triggered by the relative language proficiency and communication style differences and they are felt by both native and non-native speakers as tension. As individuals with different cultural backgrounds proceed to appraise their potential to address language standardization, the felt tension develops into a cultural predisposition towards discrete emotional experiences, and influences the individual's 
intercultural communication behavior in the way that is consistent with the appraisal themes of the triggered emotion. Our study generates wider questions and understandings of the role of emotions in intercultural communication. By examining the process of how employees in multinationals feel about language standardization, our study not only highlights the multifaceted nature of language in MNE operation (Brannen et al., 2014), but it also explains when and how language difference matters (Janssens et al., 2004). Our findings have several theoretical implications.

Intercultural Communication: Despite its centrality to MNE operation, intercultural business communication has received only limited attention in the mainstream IB literature. Influenced by intercultural communication theory (i.e., Hall, 1976), extant research on MNE communication primarily focuses on the challenge of meaning co-construction due to the cultural knowledge, language difference and communication style (Nardon, 2011). However, the emotional component of intercultural, cross-lingual communication has not been addressed explicitly. To fill this gap, our research uses MNE knowledge transfer as an act of intercultural communication where the asymmetry of corporate language proficiency set up a salient functional and psychological condition for intense emotional reactions (Hinds et al., 2014).

We provide a model by which emotion is generated where there is an impediment to communication between individuals across cultures. As our data show, the disruptive communication behaviors such as code switching or communication avoidance develop from the spontaneous but "adaptive reactions" that characterize the felt emotions. If those emotions are not put in check, the higher order of thinking including attribution, judgement, and decision making will be distorted (Volk et al., 2014). Thus, our research supports that argument that the ability to regulate emotions is the gate-keeper of intercultural communication process (Matsumoto \& Takeuchi, 1998). 
Language research in $I B$ : Our study also contributes to the current debate on using English as lingua franca. Previous research suggests that a strong foreign language anxiety experienced by non-native English speakers interrupts the content and relationship dimension of communication (Aichhorn \& Puck, 2017). However, our results show that this anxiety was also experienced by native speakers or employees with advanced English competence in the context of knowledge transfer. Consistent with the literature on emotional contagion (Hatfield et al., 1994), a high degree of workflow inter-dependence might amplify the chances of picking up emotions from other people via unconscious mimicry. However, to understand and communicate the right emotions in multicultural, multilingual MNE context became quite challenging, thus often leading to negative emotional cycles as previous research suggests.

Following this line of inquiry, we unpack the language-induced anxiety into discrete emotional experiences with distinctive triggers and consequences. Specifically, we found that these emotions are partly culturally shaped and are a response to the specific behavior in the other culture. Following primary and secondary appraisal in emotion theory (Frijda, 1993), we further theorize that anxiety is a first order response provoking emotion in the other party as a second order reaction. This distinction helps us to understand how and when language-induced emotions could have positive or negative outcomes given the specific context.

\subsection{Limitations and suggestions for future study}

Despite its contributions, there are several limitations of this study that call for further exploration. First, we focus on the emotional experience emerging from the communication between HQ and subsidiaries. As the Chinese MNE evolves, more communication will be exchanged among the subsidiaries themselves (Bjorkman et al., 2004; Mudambi \& Navarra, 2004). Previous research has indicated that the direction of MNE knowledge flow often entails different purposes, strategies and implementation processes (Minbaeva et al., 2003; Buckley et al., 2006). It can be predicted that individuals will display different types of emotions when 
they are interacting with colleagues from other subsidiaries. Future research could explicitly investigate the link between language-induced emotions and specific types of MNE communication.

Second, this research is a qualitative single case study with a small number of interviews. Although the aim of the qualitative case study is geared to theoretical generalization (Yin, 2009), the theoretical insights require further empirical testing in other international business contexts, possibly using survey data.

Third, we were not able to deal with internal variability in social background in both native English and Chinese speakers but this would be an interesting avenue to be explored by future research, for example in terms of how local dialects might have caused variations in emotional responses of the interviewees.

Fourth, our case company is an unsophisticated firm and consequently the predominance of negative emotions that emerged from our data could be a result of the firm's lack of international experience and cultural awareness. Future studies might explore language standardization in more sophisticated firms' contexts and the emotional responses it generates.

Finally, the measurement and explanation of emotional experience is a challenging research endeavor. Although the qualitative case study method, backed up with Nvivo software, enables a better matching between the core appraisal dimensions of emotion and interviewee's narrative account, multiple ways to measure emotion such as decoding of facial/vocal expressions, physiological measurement of bodily change and even neuro-imaging of brain activity might be considered (Lewis et al., 2008). This could significantly enhance the internal validity of empirical research in international business.

\subsection{Managerial implications}


Our study demonstrates that using English as lingua franca generates emotional stress not only in non-native but also in native English speakers. This means that emotions generated as a response to language standardization in the context of knowledge transfer can lead to variety of outcomes in intercultural communication. The utility of our framework is that it generates the need for contingency planning by the managers in MNEs, because while the specific outcomes cannot be anticipated, it can be expected that the imposition of a common language will generate emotions on both sides, if not effectively managed (as exemplified in the case of our firm under investigation). Our findings therefore suggest a number of important managerial implications for multinational enterprises who wish to improve the quality of their intercultural communication.

First, the cognitive capability aspects intermediating the relationship between cultural predisposition and the efficacy of an individual's intercultural communication demonstrate the need for a strategic choice of the right people to be in a position where they can be cultural intermediaries in intercultural communication, i.e., individuals who would be familiar with both cultures. Greater familiarity can be expected to enhance greater accuracy and efficacy in the recognition of emotions in the intercultural setting.

Second, our study shows that anxiety is an individual's natural initial response in dealing with intercultural communication and therefore multinationals can help managers and employees to understand better the tensions arising from the language mandate. Multinational enterprises can provide training tailored to the individuals' cultural background so that they will not feel overwhelmed by the imposition of a common language (e.g., preparation, not taking things personally, etc).

Third, our study identifies the dominant types of emotions and their influence on intercultural business communication. Multinational enterprises can use these findings as a 
starting-point to strategically "cool down" some emotions or "warm up" (bring out) others to enhance the effectiveness of global collaboration.

Fourth, language standardization can only be successful when supported by adequate intercultural communication training. Our study indicates that such training should be tailored to individuals according to their cultural predisposition. In case of "non-conforming-to-groupnorms" cultures formal cultural awareness training would be advisable while in the case of "conforming-to-group-norms" cultures intercultural awareness should be developed in more indirect ways through socialization. Good management needs to recognize the importance of socialization and bringing people from different cultures together to facilitate tacit knowledge transfer, which is essential for the protagonists to be able to interpret the emotional meaning of what is being communicated.

Fifth, the long run implications of our theorizing are that intervention is needed by top management to address the damage caused by the employees' unwillingness to communicate across cultural boundaries and to prevent "cultural insulation".

This work was supported by the Sino-British Fellowship Trust; and the Leeds University Business School.

\section{References:}

Abrams, L. C., Cross, R., Lesser, E., \& Levin D. Z. (2003). Nurturing interpersonal trust in knowledge-sharing network. Academy of Management Executive, 17: 64-77.

Aichhorn, N., \& Puck, J. (2017). 'I just don't feel comfortable speaking English': Foreign language anxiety as a catalyst for spoken-language barriers in MNCs. International Business Review 26: 749-736.

Altheide, D. L. (1996). Qualitative media analysis. Newbury Park, CA: Sage.

Argote, L., \& Ingram, P. (2000). Knowledge transfer: A basis for competitive advantage in firms. Organizational Behaviour and Human Decision Processes, 82: 150-169. 
Auer, P. J. C. (2000). A conversation analytic approach to code-switching and transfer. In L. Wei (Ed.), The Bilingualism Reader. London and New York: Routledge: 166-187.

Bagozzi, R. P., Gopinath, M., \& Nyer, P. U. (1999). The role of emotions in marketing. Journal of the Academy of Marketing Science, 27: 184-206.

Barsade, S. G., \& Gibson, D. E. (2007). Why does affect matter in organizations? Academy of Management Perspective, 21: 36-59.

Becker-Ritterspach, F. A. (2006). The social constitution of knowledge integration in MNEs: A theoretical framework. Journal of International Management, 12: 358-377.

Bhagat, R. S., Kedia, B. L., Harveston, P. D., \& Triandis, H. C. (2002). Cultural variations in the cross-border transfer of organizational knowledge: An integrative framework. Academy of Management Review, 27: 204-221.

Bird, A., Osland, J. S., Mendenhall, M., \& Schneider, S. C. (1999). Adapting and adjusting to other cultures: what we know but don't always tell. Journal of Management Inquiry, 8: 152-166.

Birkinshaw. J., Brannen M. Y., \& Tung, R. L. (2011). From a distance and generalization to up close and grounded: Reclaiming a place for qualitative methods in international business research. Journal of International Business Studies, 42: 573-581.

Bjorkman, I. Barner-Rasmussen., \& Li, L. (2004). Managing knowledge transfer in MNCs: The impact of headquarters control mechanism. Journal of International Business Studies, 25: 443-455.

Blumer, H (1969). Symbolic Interactionism: Perspective and Method. Berkeley: University Of California Press.

Brannen, M. Y. (2004). When Mickey loses face: Recontextualization, semantic fit, and the semiotics of foreignness. Academy of Management Review, 29: 593-616.

Brannen, M. Y., \& Doz, Y. L. (2010). From a distance and detached to up close and personal: Bridging strategic and cross-cultural perspectives in international management research and practice. Scandinavian Journal of Management, 26: 236-247.

Brannen, M. Y., Piekkari, R., \& Tietze, S. (2014). The multifaceted role of language in international business: Unpacking the forms, functions, and features of a critical challenge to MNC theory and performance. Journal of International Business Studies, 45: 495-507.

Brown, J. S. \& Duguid, P. (2001). Knowledge and organization: A social-practice perspective. Organization Science, 12: 198-213.

Buckley, P. J., \& Carter, M. J. (2004). A formal analysis of knowledge combination in multinational enterprises. Journal of International Business Studies, 35: 371-384.

Buckley, P. J., Carter, M. J., Clegg, J., \& Tan, H. (2005). Language and social knowledge in foreign knowledge transfer to China. International Studies of Management \& Organization, 35: 47-64.

Buckley, P. J., Clegg, J., \& Tan, H. (2006). Cultural awareness in knowledge transfer to China - The role of guanxi and mianzi. Journal of World Business, 41: 275-288.

Chua, R. Y. J., Morris, M. W., \& Ingram, P. (2009). Guanxi vs networking: Distinctive configurations of affect- and cognition-based trust in the networks of Chinese vs American managers. Journal of International Business Studies, 40: 490-508. 
Corbin, J., \& Strauss, A. (2008). Basics of Qualitative Research: Techniques and Procedures for Developing Grounded Theory, $3^{\text {rd }}$ Edition Thousand Oaks, CA: Sage.

Cohen, W. M., \& Levinthal, D. A. (1990). Absorptive capability: A new perspective on learning and innovation. Administrative Science Quarterly, 35: 128-152.

Crysal, D. (1997). English as a global language. $2^{\text {nd }}$ Ed, Cambridge University Press.

Durand, M. (2016). Employing critical incident techniques as one way to display the hidden aspects of post-merger integration. International Business Review, 25: 87-102.

Duranti, A. (1997). Linguistic anthropology. Cambridge UK: Cambridge University Press.

Eid, M., \& Diener, E. (2001). Norms for experiencing emotions in different cultures: Inter- and Intranational differences. Journal of Personality and Social Psychology, 81: 869-885.

Ekman, P. (1992). An argument for basic emotions. Cognition \& Emotion, 6: 169-200.

Elfenbein, H. A. (2007). Emotion in organization, Academy of Management Annals, 1: 315386.

Ellsworth, P. C., \& Scherer, K. R. (2003). Appraisal processes in emotion. In R. J. Davidson, K. R. Scherer, \& H.H., Goldsmith (Eds), Handbook of affective science. Oxford: Oxford University Press: 572-595.

Ellsworth, P. C. (1994). Sense, Culture and Sensitivity. In S. Kitayama, \& H. Markus (Eds), Emotion and culture: Empirical studies of mutual influence. Washington, DC: APA: 2350.

Feather, N. T. \& Sherman, R. (2002). Envy, resentment, schadenfreude, and sympathy: Reactions to deserved and undeserved achievement and subsequent failure. Personality and Social Psychology Bulletin, 28: 953-961.

Fiske, A.P., Kitayama, S., Markus, H, R., \& Nisbett, R. E. (1998). The cultural matrix of social psychology, In D. T. Gilbert, S. T. Fiske, \& G. Lindzey (Eds.), The handbook of social psychology. New York: McGraw-Hill: 915-981.

Fletcher, M., \& Plakoyiannaki, E. (2011). Case selection in international business: key issues and common misconceptions. In R, Piekkari., \& C, Welch (Eds.), Rethinking the case study in international business and management research. Edwards Elgar Publishing: 171-173.

Fredriksson, R., Barner-Rasmussen, W., \& Piekkari, R. (2006). The multinational corporation as a multilingual organization. The notion of a common corporate language. Corporate Communications: An International Journal, 11: 406-423.

Frijda, N. H. (1986). The Emotions. Cambridge: Cambridge University Press.

Frijda, N. H., Kuipers, P., \& ter Schure, E. (1989). Relations among emotion, appraisal, and emotion action readiness. Journal of Personality and Social Psychology, 57: 212-228.

Geertz, C. (1973). The Interpretation of Cultures. Basic Books.

Gephart, R. P. (2004). Qualitative research and the Academy of Management Journal. Academy of Management Journal, 47: 452-462.

Gherardi, S. (2006). Organizational knowledge The texture of workplace learning: Blackwell Publishing, Malden.

Gioia, D. A., Corley, K. G., \& Hamilton, A. L. (2013). Seeking qualitative rigor in inductive research notes on the Gioia methodology. Organizational Research Methods, 16: 15- 
31.

Goetz, J.L., Keltner, D., \& Simon-Thomas, E. (2010). Compassion: An evolutionary analysis and empirical review. Psychological Bulletin, 136: 351-374.

Goodall, K., \& Roberts, J. (2003). Only connect: Teamwork in the multinational. Journal of World Business, 38: 150-164.

Greenberg, M. S. (1980). A theory of indebtedness. Social Exchange: 3-26.

Gross, J. J., \& Tommpson, R. A. (2007). Emotion regulation: Conceptual foundations, In J.J. Gross (Ed.), Handbook of emotion regulation. New York: Guildford Press: 3-24.

Gooty, J., Gavin M., \& Ashkansy N. M. (2009). Emotions research in OB: The challenges that lie ahead. Journal of Organizational Behavior, 30: 833-838.

Gudykunst, W. B., \& Kim, Y. Y. (2002). Communicating with strangers: An approach to Intercultural communication. McGraw Hill, London.

Gupta, A. K., \& Govindarajan, V. (2000). Knowledge flow within multinational corporations. Strategic Management Journal, 21: 473-496.

Hadjichristidis, C., Geipel, J., \& Surian, L. (2017). How foreign language affects decisions: Rethinking the brain-drain model. Journal of International Business Studies, 48: 645651.

Hall, E. T. (1976). Beyond Culture. Achor Books, New York.

Harzing, A.-W., \& Feely, A. J. (2008). The language barrier and its implication for HQsubsidiary relationships. Cross Cultural Management: An International Journal, 15: 49-61.

Harzing, A-W., \& Pudelko, M. (2014) Hablas vielleicht un peu la mia language? A comprehensive overview of the role of language difference in headquarters-subsidiary communication. The International Journal of Human Resource Management, 25: 696717.

Hatfield, E., Cacioppo, J. T., \& Rapson, R. L. (1994). Emotional Contagion. Cambridge University Press.

Henderson, J. K. (2005). Language diversity in international management teams. International Studies of Management \& Organization, 35: 66-82.

Hidi, S. \& Renninger, K. A. (2006). The four-phase model of interest development. Education Psychologist, 4: 111-127.

Hinds, P. J., Neeley, T. B., \& Cramton, C. D. (2014). Language as a lightning rod: Power contests, emotion regulation, and subgroup dynamics in global teams. Journal of International Business Studies, 45: 536-561.

Hong, J. F. L., \& Nguyen, T. V. (2009). Knowledge embeddedness and the transfer mechanisms in multinational corporations. Journal of World Business, 44: 347-356.

Hong, J. F. L., Snell, R. S., \& Easterby-Smith, M. (2009). Knowledge flow and boundary crossing at the periphery of a MNC. International Business Review, 18: 539-554.

Imada, T., \& Ellsworth, P. C. (2011). Proud Americans and lucky Japanese: cultural differences in appraisal and corresponding emotion. Emotion, 11: 329-345. 
Janssens, M., Lambert, J., \& Steyaert, C. (2004). Developing language strategies for international companies: the contribution of translation studies. Journal of World Business, 39: 414-430.

Janssen, M., \& Steyaert, C. (2014). Developing language strategies for international companies: towards a multilingual franca approach in international business studies. Journal of International Business Studies, 45: 623-639.

Ji, L.-J., Zhang, Z. \& Nisbett, R.E. (2004). Is It Culture or Is It Language? Examination of Language Effects in Cross-Cultural Research on Categorization. Journal of Personality and Social Psychology, 87: 57-65.

Jiang, W. (2000). The relationship between culture and language. ELT Journal, 54: 328-334.

Joshi, A. M., \& Lahiri, N. (2014). Language friction and partner selection in cross-border R\&D alliance formation. Journal of International Business Studies, 46: 123-152.

Keltner, D., \& Haidt, J. (1999). Social functions of emotions at four levels of analysis. Cognition and Emotion 13: 505-521.

Kim, Y. Y., \& Gudykunst, W. B. (1988). Theories in Intercultural Communication. Sage Publications.

Kitayama, S., Markus, M. H., Matsumoto, H., Norasakkunkit, V. (1997). Individual and collective processes in the construction of the self: self-enhancement in the United States and self-criticism in Japan. Journal of Personality and Social Psychology, 72: 1245-1267.

Kitayama, S., Markus, H. R., \& Kurokawa, M. (2000). Culture, emotion, and well-being: Good feelings in Japan and the United States. Cognition \& Emotion, 14: 93-124.

Kitayama, S., Mesquita B., \& Karasawa, M. (2006). Cultural affordance and emotional experience: Socially engaging and disengaging emotions in Japan and the United States. Journal of Personality and Social Psychology, 91: 890-903.

Kogut, B. \& Zander, U. (1993). Knowledge of the firm and evolutionary theory of the multinational corporation. Journal of International Business Studies, 24: 625-645.

Kogut, B., \& Zander, U. (1996). What firms do? Coordination, identity and learning. Organization Science, 7: 502-518.

Lazarus, R. S. (1991). Emotion and adaption. New York: Oxford University Press.

Lerner, J. S. \& Tiedens, L. Z. (2006). Portrait of the angry decision maker: How appraisal tendencies shape anger's influence on cognition. Journal of Behavioral Decision Making, 19: 115-137.

Levin, D. Z., Kurtzberg, T, R., Phillips, K. W., \& Lount, R. B. (2010). The role of affect in knowledge transfer. Group Dynamics: Theory, Research and Practice, 14: 123-142.

Levina, N., \& Ross, J.W. (2003). From the vendor's perspective: exploring the value proposition in information technology outsourcing. MIS Quarterly, 27: 331-364.

Locke, K. D. (2001). Grounded theory in management research. Thousand Oaks, CA: Sage.

Loewenstein, G. (1996). Out of control: Visceral influences on behavior. Organizational Behavior and Human Decision Processes, 65: 272-292.

Loewenstein, G. (2007). Affect regulation and affective forecasting, In J.J. Gross (Ed.), Handbook of emotion regulation (pp. 180-203). New York: Guilford. 
Maass, A., Karasawa, M., Politi, F., \& Suga, S. (2006). Do verbs and adjectives play different roles in different cultures? A cross-linguistic analysis of person representation. Journal of Personality and Social Psychology, 90: 734-750.

Manstead, A. S. R., \& Fischer, A. H. (2002). Beyond the universality-specificity dichotomy. Cognition and Emotion, 16: 1-9.

Markus H.R., \& Kitayama S. (1991). Culture and the self: implication for cognition, emotion and motivation. Psychological Review, 98: 224-253.

Marschan-Piekkari, R., Welch, D. E., \& Welch, L. S. (1999a). In the shadow: The impact of language on structure, power and communication in the multinational. International Business Review, 8: 421-440.

Marschan-Piekkari, R., Welch, D. E., \& Welch, L. S. (1999b). Adopting a common corporate language: IHRM implications. International Journal of Human Resource Management, 10: 377-390.

Mason, J. (2002). Qualitative Researching 2nd edition. Sage Publications.

Matsumoto, D., You S. H., \& LeRoux, J. A. (2007). Emotion and intercultural adjustment. In H. Kotthoff., \& H. Spencer-Oatey (eds). Handbook of Intercultural Communication, Mouton de Gruyter: 77-98.

Mauss, I. B., \& Robinson, M. D. (2009): Measures of emotion: A review. Cognition and Emotion, 23: 209-237.

Mesquita, B., \& Frijda, N. (1992). Cultural variations in emotions: a review. Psychological Bulletin, 112: 179-204.

Mesquita, B., \& Ellsworth, P. (2001). The role of culture in appraisal, In K. R. Scherer \& A. Schorr (Eds.), Appraisal processes in emotion: Theory, method, research. New York: Oxford University Press: 233-247.

Mesquita, B. (2001). Emotions in collectivist and individualist contexts. Journal of Personality and Social Psychology, 80: 68-74.

Mesquita, B., \& Boiger, M. (2014). Emotions in context: A sociodynamic model of emotions. Emotion Review, 6: 298-302.

Michailova, S., Piekkari. R., Plakoyiannaki, E., Ritvala, T., Mihailova, I., \& Salmi, A. (2014). Breaking the silence about exiting fieldwork: A relational approach and its implications for theorizing. Academy of Management Review, 29: 139-161.

Minbaeva, D., Pedersen, T., Bjorkman., I., Fey, C. F., \& Park, H. J. (2003). MNC knowledge transfer, subsidiary absorptive capability, and HRM. Journal of International Business Studies, 24: 586-599.

Mudambi, R., \& Navarra, P. (2004). Is knowledge power? Knowledge flows, subsidiary power and rent-seeking within MNCs. Journal of International Business Studies, 35: 385-406.

Nardon, L., Steers, R., \& Sanchez-Runde, C. (2011). Seeking common ground: Strategies for enhancing multicultural communication. Organizational Dynamics, 40: 85-95.

Neeley, T. B., Hinds, P. J., \& Cramton, C. D. (2012). The (un)hidden turmoil of language in global collaboration. Organization Dynamics, 41: 236-224.

Neeley, T. B., \& Dumas, T. L. (2016). Unearned statues gain: Evidence from a global language mandate. Academy of Management Journal, 59: 14-43. 
Nisbett R., Peng, K., Choi, I., \& Norenzayan, A. (2001). Culture and systems of thought: Holistic versus analytic cognition. Psychological Review, 108: 291-310.

Nurmi, N. \& Hinds, P. J. (2016). Job complexity and learning opportunities: A silver lining in the design of global virtual work. Journal of International Business Studies, 47: 631654.

Orlikowski, W. J. (1992). Knowing in practice: enacting ac collective capability in distributed organizing. Organization Science, 13: 249-273.

Oshri, I, Kotlarsky, J., \& Willcocks, L. P. (2015). The Handbook of Global Outsourcing and Offshoring 3rd Edition, Palgrave Macmillan.

Oveis, C., Horberg. E. J., \& Keltner, D. (2010). Compassion, Pride, and Social Intuitions of self-other similarity. Journal of Personality \& Social Psychology, 98: 618-630.

Patton, M. Q. (1980). Qualitative evaluation and research methods, $2^{\text {nd }}$ edition. Beverly Hills, CA: Sage.

Peltokorpi, V. (2010). Intercultural communication in foreign subsidiaries: The influence of expatriate's language and cultural competences. Scandinavian Journal of Management, 26: 176-188.

Peltokorpi, V., \& Yamao S. (2017). Corporate language proficiency in reverse knowledge transfer: A moderated mediation model of shared vision and communication frequency. Journal of World Business, 52: 404-416.

Piekkari, R., Vaara, E., Tienari, J., \& Santti, R. (2005). Integration or disintegration? Human resource implications of a common corporate language decision in a cross-border merger. International Journal of Human Resource Management, 16: 330-344.

Rime, B. (2009). Emotion elicits the social sharing of emotion: Theory and empirical review. Emotion Review, 1: 60-85.

Robinson, M. D., \& Clore, G. L. (2002). Belief and Feeling: evidence for an accessibility model of emotional self-report. Psychological Bulletin, 128: 934-960.

Roseman. I. J. (2011). Emotional Behaviors, Emotivational Goals, Emotion Strategies: Multiple Levels of Organization Integrate Variable and Consistent Responses. Emotion Review, 3: 434-443.

Roseman. I. J. (2013). Appraisal in the emotion system: Coherence in strategies for coping. Emotion Review, 5: 141-139.

Sapir, E. (1921). Language. New York, NY: Harcourt Brace.

Scherer, K. R. (2005). What are emotions? And how can they be measured? Social Science Information, 44: 695-729.

Schomaker, M. S., \& Zaheer, S. (2014). The role of language in knowledge transfer to geographically dispersed manufacturing operations. Journal of International Management, 20: 55-72.

Shannon, C.E., \& Weaver, W. (1949). The Mathematic Theory of Communication. Urbana, IL: University of Illinois Press.

Silvia, P. J. (2005). What is interesting? Exploring the appraisal structure of interest. Emotion, 5: 89-102.

Sims, T., \& Tsai, J. L. (2015). Patients respond more positively to physicians who focus on 
their ideal affect. Emotion, 15: 303-318

Smith, C. A. \& Ellsworth, P. C. (1985). Patterns of cognitive appraisal in emotion. Journal of Personality and Social Psychology, 48: 813-838.

Smith, C. A., \& Lazarus, R. S. (1993). Appraisal components, core relational themes, and the emotions. Cognition and Emotion, 7: 233-269.

Stephan, C. W., Helms, M. M., \& Haynes, P. J. (1995). Intercultural anxiety: Implication for improving expatriate selection for Japan. Cross Cultural Management: An International Journal, 2: 25-32.

Steyaert, C., Ostendorp, A., \& Gaibrois, C. (2011). Multilingual organization as 'linguascapes': Negotiation the position of English through discursive practices. Journal of World Business, 46: 270-278.

$\mathrm{Su}, \mathrm{N}$. (2013). Internationalization strategies of Chinese IT service suppliers. MIS Quarterly, 37: $175-200$.

Swedberg, R. (2012). Theorizing in sociology and social science: Turning to the context of discovery. Theory and Society, 41: 1-40

Szulanski, G. (1996). Exploring internal stickiness: Impediments to the transfer of best practice within the firm. Strategic Management Journal, 17: 27-43.

Taylor S., \& Osland, J. (2003). The impact of intercultural communication on global organizational learning. In M. Easterby-Smith, \& M. A. Lyles (Eds) Handbook of Organizational Learning and Knowledge Management, Blackwell Publishing: 212232.

Tangney, J. P. (1992). Situational determinants of shame and guilt in young adulthood. Journal of Personality and Social Psychology, 61: 589-607.

Tangney, J. P., Miller, R. S., Flicker, L., \& Barlow, D, H. (1996). Are Shame, Guilt and Embarrassment distinct emotions? Journal of Personality and Social Psychology, 70: 1256-1269.

Tenzer, H., Pudelko, M., \& Harzing, A-W. (2014). The impact of language barriers on trust formation in multinational teams. Journal of International Business Studies, 45: 508535.

Tenzer, H., \& Pudelko, M. (2015). Leading across language barriers: Managing languageinduced emotions in multinational teams. The Leadership Quarterly, 26: 606-625.

Tenzer, H., Terjesen, S., \& Harzing, A-W. (2017). Language in International Business: A review and agenda for future research. Management International Review 57: 815-854.

Tenzer, H., \& Pudelko, M. (2017). The influence of language difference on power dynamics in multinational teams. Journal of World Business, 52: 45-61.

Thompson, N. (2003). Communication and Language: A handbook of theory and practice. Palgrave MacMillan.

Tsai, J. L., Knutson, B., \& Fung, H. (2006). Cultural variation in affect valuation. Journal of Personality and Social Psychology, 90: 288-307.

Tsai, W., \& Ghoshal, S. (1998). Social capital and value creation: The role of intrafirm networks. Academy of Management Journal, 41: 464-476.

Tubbs, S.L. \& Moss, S. (2003). Human Communication: Principles and context. $9^{\text {th }}$ ed. New 
York: McGraw-Hill.

Tulving, E. (2002). Episodic memory: From mind to brain. Annual Review of Psychology, 53: $1-25$.

Vaara, E., Tienari, J., Piekkari, R., \& Santti, R (2005). Language and the circuits of power in merging multinational corporation. Journal of Management Studies, 42: 595-623.

Verbeke, A. (2010). International acquisition success: Social community and dominant logic dimensions. Journal of International Business Studies, 45: 862-885.

Volk, S., Kohler., T., \& Pudelko, M. (2014). Brain drain: The cognitive neuroscience of foreign language processing in multinational corporations. Journal of International Business Studies, 45: 862-885.

Von Glinow, M. A., Shapiro, D.L., \& Brett, J. M. (2004). Can we talk and should we? Managing emotion conflicts in multicultural team. Academy of Management Review, 29: $578-592$.

Vuori, T. O., \& Huy, Q. N. (2016). Distributed attention and shared emotions in the innovation process: How Nokia lost Smartphone battle. Administrative Science Quarterly, 61: 951.

Watkins, P., Scheer, J., Ovnicek, M., \& Kolts, R. (2006). The debt of gratitude: Dissociating gratitude and indebtedness. Cognition \& Emotion, 20: 217-241.

Welch, C., \& Piekkari, R. (2006). Crossing language boundaries: qualitative interviewing in international business. Management International Review, 46: 417-437.

Welch, C., Piekkari, R., Plakoyiannaki, E., Paavilainen-Mantymaki. E. (2011). Theorising from case studies: Towards a pluralist future for international business research, Journal of International Business Studies, 42: 740-762.

Welch, D. E., \& Welch, L. S. (2008). The impact of language in international knowledge transfer. Management International Review, 48: 339-360.

Werner, O., \& Schoepfle, G. M. (1987). Systematic fieldwork. 2 vols. Beverly Hills, CA: Sage.

West, R., \& Turner, L. H. (2003). Introducing communication theory: analysis and application. McGraw-Hill Higher Education.

Whorf, B. L. (1956). Language, thought, and reality: Selected writings of Benjamin Lee Whorf. New York: Wiley: Chapman \& Hall.

Yamao, S., \& Sekiguchi, T. (2015). Employee commitment to corporate globalization: The role of English proficiency and human resource practices. Journal of World Business, 50: 168-179.

Yin. R. K. (1994). Case Study Research: Design and Methods, $2^{\text {nd }}$ edition. London: Sage.

Zaidman, N., \& Brock, D. M. (2009). Knowledge transfer within multinationals and their foreign subsidiaries: A cultural-context approach. Group \& Organization Management, 34: 297-329. 


\section{Figure 1}

Representation of Received Theory: The Standard Model of Language Standardization Underlying the Intercultural Communication Process within an MNE.

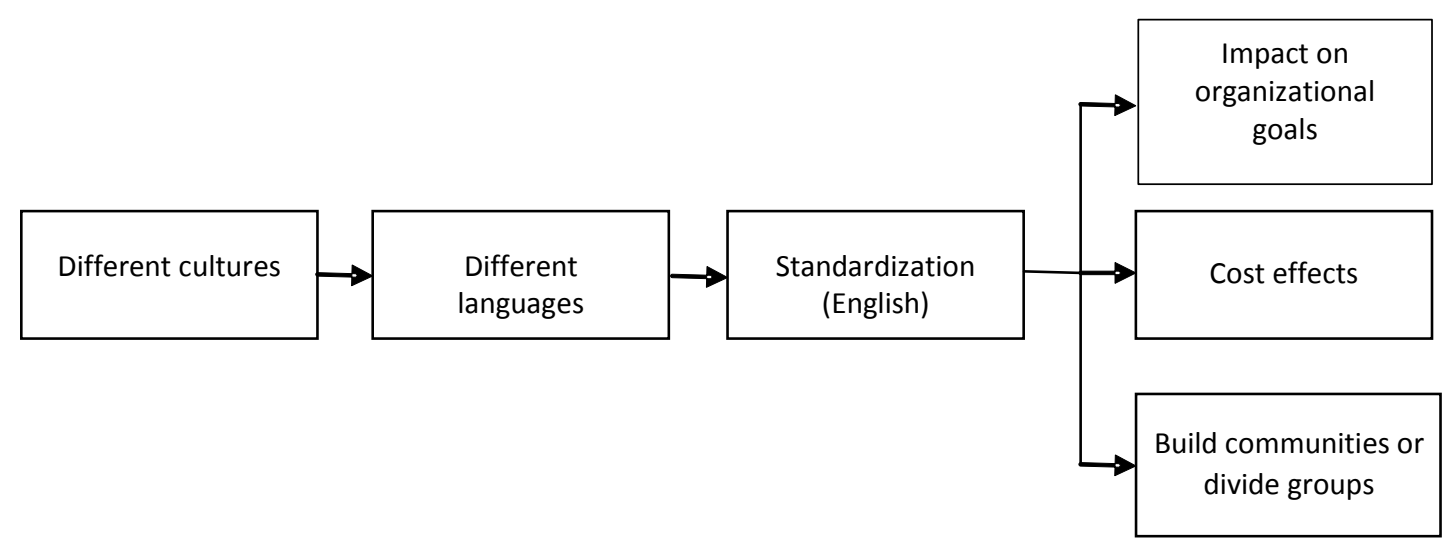


Figure 2

Theory Extension: Intermediary Role of Emotions in Language Standardization Underlying the Intercultural Communication Process within an MNE.

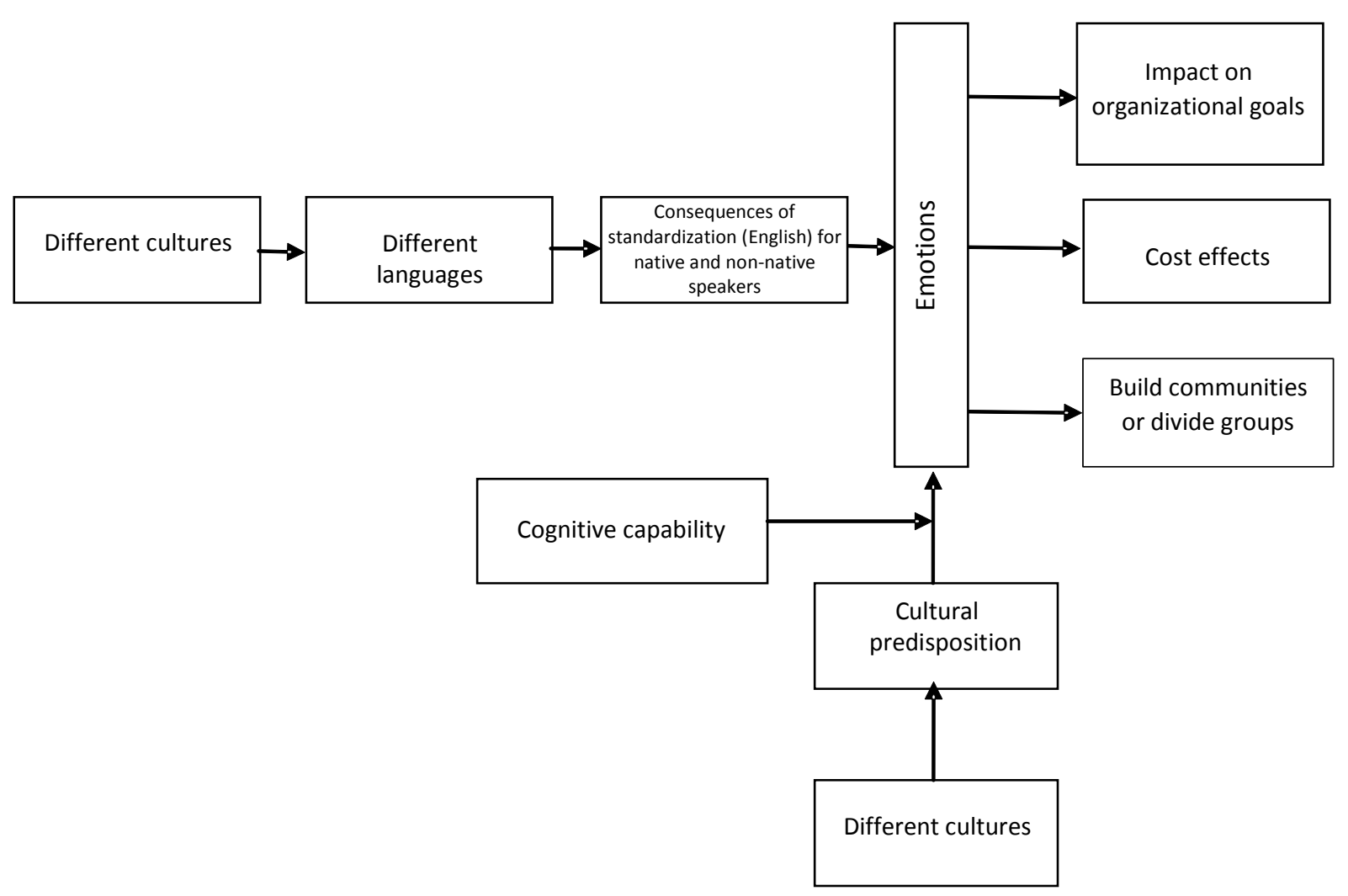


Table 1: Profile of Subsidiary Interviewees

\begin{tabular}{|c|c|c|c|c|c|c|}
\hline $\begin{array}{l}\text { Interview } \\
\text { Number } \\
\end{array}$ & Nationality & Job Title & Level & $\begin{array}{c}\text { Tenure } \\
\text { (Year/Month) } \\
\end{array}$ & Business Unit & Previous work \\
\hline 1 & Australian & Marketing Manager & Middle & 1.5 & BG6 & Project Manager \\
\hline 2 & Australian & HR Director & Top & 1.5 & BG6 & Chief Operating Officer \\
\hline 3 & Australian & Associate Vice President & Top & 3.7 & BG6 & Senior Manager \\
\hline 4 & Australian & Sales representative & Operating & 1 & BG6 & Managing Director \\
\hline 5 & Australian & Developer & Operating & 0.9 & BG6 & Data Integration specialist \\
\hline 6 & Australian & Account Manager & Middle & 1 & BG6 & Technical Lead \\
\hline 7 & Australian & Senior Vice President & Top & 3 & BG6 & Chief Executive Officer \\
\hline 8 & American & Testing Manager & Operating & 1 & BG3 & Principle Testing Manager \\
\hline 9 & American & Delivery Manager & Operating & 1 & BG3 & Project Manager \\
\hline 10 & American & UX Manager & Middle & 4.5 & BG3 & Market analysts \\
\hline 11 & American & Sales director & Middle & 1 & $\mathrm{BG} 2$ & Business Director \\
\hline 12 & American & Chief officer of POM & Top & 4 & BG3 & Project Manager \\
\hline 13 & American & Marketing Analyst & Operating & 1.9 & Marketing & Internship in PR \\
\hline 14 & American & IT manager & Middle & 3.5 & BG1 & Technology coordinator \\
\hline 15 & American & Sales director & Middle & 1.8 & BG1 & Marketing director \\
\hline 16 & American & Senior delivery director & Top & 2.2 & BG4 & IT consult \\
\hline 17 & European (Finnish) & Sale representative & Operating & 1.2 & BG2 & Account Manager \\
\hline 18 & European (Spanish) & Head of Vendor Manager & Middle & 2.5 & PGS & Vendor Manager \\
\hline 19 & European (Spanish) & Director of translation & Middle & 2.5 & PGS & Delivery manager \\
\hline 20 & European (Swedish) & Associated vice president & Top & 3 & PGS & Senior director of PGS \\
\hline 21 & European (German) & Sales Representative & Operating & 2 & PGD & Sales \\
\hline 22 & European (British) & General Manager in Europe & Top & 2 & SBU & Chief executive officer \\
\hline 23 & European (British) & Sales Representative & Operating & 1 & SBU & Sales assistant \\
\hline
\end{tabular}


Table 2: Profile of HQ Interviewees.

\begin{tabular}{|c|c|c|c|c|c|c|}
\hline $\begin{array}{l}\text { Interview } \\
\text { Number } \\
\end{array}$ & Nationality & Job Title & Level & $\begin{array}{c}\text { Tenure } \\
\text { (Year/Month) }\end{array}$ & Business Unit & Previous work \\
\hline 1 & Chinese & Project Management & Middle & 7 & PGS & Freelance Translator \\
\hline 2 & Chinese & Translation Production Lead & Middle & 6 & PGS & Translator \\
\hline 3 & Chinese & Team Manager & Middle & 5 & PGS & Translation Lead \\
\hline 4 & Chinese & Vendor Management & Middle & 5 & PGS & Vendor Management \\
\hline 5 & Chinese & Project Lead & Operating & 1 & PGS & Translator \\
\hline 6 & Chinese & Project Lead & Operating & 3 & PGS & Project Assistant \\
\hline 7 & Chinese & Vendor Management & Operating & 3.5 & PGS & I.T. and Management \\
\hline 8 & Chinese & Associate VP of Business solutions & Top & 2 & $\mathrm{BG} 2$ & Firmware Architect \\
\hline 9 & Chinese & Manager of Business Solution & Middle & 6 & $\mathrm{BG} 2$ & Delivery Manager \\
\hline 10 & Chinese & Presales & Middle & 4 & BG2 & QA Lead \\
\hline 11 & Chinese & Account Manager & Middle & 5 & $\mathrm{BG} 2$ & Software Architect \\
\hline 12 & Chinese & Presales & Operating & 5 & BG2 & IT Testing Engineer \\
\hline 13 & Chinese & UX Designer & Operating & 1 & BG2 & Website designer \\
\hline 14 & Chinese & Market assistant & Operating & 1.2 & Marketing & Marketing \\
\hline 15 & Chinese & Market analyst & Operating & 2 & Marketing & Market assistant \\
\hline 16 & Chinese & Market Director & Middle & 2 & Marketing & Marketing Manager \\
\hline 17 & Chinese & Associate VP & Top & 3 & Marketing & Market analyst \\
\hline 18 & Chinese & Senior VP of Business development & Top & 3 & BG3 & Co-founder of an I.T. firm \\
\hline 19 & Chinese & $\mathrm{VP}$ of strategic client & Top & 3 & BG3 & Co-founder of an I.T. firm \\
\hline 20 & Chinese & Associate VP of Business & Top & 4 & BG3 & R\&D Lead \\
\hline
\end{tabular}




\begin{tabular}{|c|c|c|c|c|c|c|}
\hline $\begin{array}{l}\text { Interview } \\
\text { Number } \\
\end{array}$ & Nationality & Job Title & Level & $\begin{array}{c}\text { Tenure } \\
\text { (Year/Month) }\end{array}$ & Business Unit & Previous work \\
\hline 21 & Chinese & Associate VP of Business Operation & Top & 7 & BG3 & Business Operation \\
\hline 22 & Chinese & Associate VP of Business Operation & Top & 10 & BG3 & Owner of private firm \\
\hline 23 & Chinese & Business Operation & Middle & 7 & BG3 & Project Lead \\
\hline 24 & Chinese & Strategic Alliance & Middle & 5 & BG3 & Pre-sales \\
\hline 25 & Chinese & Presales & Operating & 3.5 & BG3 & Project assistant \\
\hline 26 & Chinese & Business Operation & Operating & 1 & BG3 & Customer engagement \\
\hline 27 & Chinese & VP & Top & 16 & BG5 & Software Engineer \\
\hline 28 & Chinese & Senior Project Manager & Middle & 3 & BG6 & Project Manager \\
\hline 29 & Chinese & Technical Lead & Operating & 1 & BG6 & I.T. Engineer \\
\hline 30 & Malaysian/Chinese & Business Operation & Middle & 4 & BG6 & HR \\
\hline 31 & Malaysian/Chinese & Business Operation & Middle & 5 & BG6 & Account Manager \\
\hline 32 & Singaporean/Chinese & HR manager & Middle & 3 & BG6 & Project Manager \\
\hline 33 & Chinese & Associate VP & Top & 12 & BG7 & Business Operation \\
\hline 34 & Chines & Sales & Middle & 3 & BG7 & Project Manager \\
\hline 35 & Chinese & Sales & Operating & 1 & BG7 & Accountant \\
\hline 36 & Chinese & Market analyst & Operating & 0.8 & SBU & Market Intern \\
\hline 37 & Chinese & Marketing manager & Middle & 2 & SBU & Marketing \\
\hline
\end{tabular}


Table 3: Critical incidents in knowledge communication

\begin{tabular}{|c|c|c|}
\hline $\begin{array}{l}\text { The type of critical incident in } \\
\text { knowledge communication }\end{array}$ & $\begin{array}{l}\text { Criticality related to English } \\
\text { as lingua franca }\end{array}$ & Quotations: Description of critical incident by the HQ staff \\
\hline $\begin{array}{l}\text { Producing the documents in written } \\
\text { English (e.g., project briefing, operation } \\
\text { manual, presentations, sales report) }\end{array}$ & A lack of English fluency & $\begin{array}{l}\text { "Writing project report in English is an absolutely nightmare. I have to rack my brains to search the word or phrase due to my limited } \\
\text { vocabulary. When starting to assemble them into sentences with right grammar, I feel already confused and exhausted about what I } \\
\text { need to explain" (\#29 Chinese). } \\
\text { "Even we spent an entire week to prepare an English version of operation manual, our American team still asked for more clarity. Now, } \\
\text { revising this manual began to take away our time to focus on other important issues" (\#23 Chinese). } \\
\text { "With the pain of writing up a 15-page marketing report in English, I had no interest at all to mention anything else outside the work } \\
\text { which was supposed to build my personal relationship with the American sales" (\#2 Chinese). }\end{array}$ \\
\hline $\begin{array}{l}\text { Expressing opinions, insights and } \\
\text { suggestions in spoken English }\end{array}$ & $\begin{array}{l}\text { Limited rhetorical skills in } \\
\text { English }\end{array}$ & $\begin{array}{l}\text { "When I introduced our core delivery service in English, I got the responses such as 'what do you mean by this idea?', 'what you are } \\
\text { trying to tell use' and 'please say it clearly', you feel inferior to defend or explain your views in front of those critical native English } \\
\text { speakers" ( } \# 29 \text { Chinese). } \\
\text { "As an expert, I was invited to talk about BPO service. However, using English simply blocked lots of my insights which could be } \\
\text { otherwise expressed in Chinese. I feel my competence was suddenly diminished because I could not speak English fluently" (\#9 } \\
\text { Chinese). }\end{array}$ \\
\hline $\begin{array}{l}\text { Understand the expression, technical } \\
\text { jargons and business terms in English }\end{array}$ & $\begin{array}{l}\text { Difficult to find out semantic } \\
\text { changes or equivalents }\end{array}$ & $\begin{array}{l}\text { "In Chinese, we use expressions such as 'you should do this' or 'you need to follow that' to ensure others that you really got a better } \\
\text { solution. However, I was surprised by the reaction of my foreign colleague who considered these expressions in English 'rude' and } \\
\text { 'intrusive"” (\#3 Chinese). } \\
\text { "We were given a task briefing which contained a quite number of technical terms nobody could explain in Chinese. When we asked } \\
\text { the Australian team for the explanation, they provided us with more unfamiliar technical terms" (\#29 Chinese). } \\
\text { "When performing QA [Quality Assessment] for I.T. language service, we only issue 'evaluation form' of our designated translators' } \\
\text { work. However, our Europen team members refuse to adopt our practice and insist that QA from their definition should incorporate } \\
\text { an additional 'editing form" (\#4 Chinese). }\end{array}$ \\
\hline $\begin{array}{l}\text { The choice of English word and sentences } \\
\text { for knowledge communication }\end{array}$ & $\begin{array}{l}\text { Challenge of explaining or } \\
\text { requesting contextual } \\
\text { knowledge with simple words. }\end{array}$ & $\begin{array}{l}\text { "The American sales keep on asking for a shorter and simple version of case study. However, I just do not think simple words and } \\
\text { short sentence are enough to provide a detailed account of what we have done here" (\#16 Chinese). } \\
\text { "Most of the foreign staff in US and Australia are either experts in a particular domain or quite senior in the job title. I was very worried } \\
\text { they would consider my request to explain the assigned task if my English was not written or spoken perfectly" (\#4 Chinese). }\end{array}$ \\
\hline $\begin{array}{l}\text { Facing communication style that } \\
\text { conflicted with 'humble', 'friendly' and } \\
\text { 'face give/saving' communication code. }\end{array}$ & $\begin{array}{l}\text { The difference in implicit } \\
\text { communication rules }\end{array}$ & $\begin{array}{l}\text { "Our culture told us that you should be humble and modest when expressing the views because there are always someone whose } \\
\text { knowledge is better than yours. However, the foreign colleagues seem to like to show off what they know about the latest technology } \\
\text { or global markets even it is quite basic or superficial from my point of view" (\#37 Chinese). } \\
\text { "Things are quite different when we have cross-border meeting with the American team. Quite often, my talk was interrupted by one } \\
\text { American colleague's question. Then another one might jump in and pose another question before I start to address previous question. } \\
\text { It is chaotic and you feel they like to attack each other" (\#24 Chinese). } \\
\text { "We did not to take the requirement to fill in project log seriously as we were not used to this practice. Then the American account } \\
\text { manager confronted with us and openly criticized our delivery work as "poorly executed" in front of BG head and other project teams" } \\
\text { (\#22 Chinese). }\end{array}$ \\
\hline
\end{tabular}




\begin{tabular}{|c|c|c|}
\hline $\begin{array}{l}\text { Type of critical incident in knowledge } \\
\text { communication }\end{array}$ & $\begin{array}{l}\text { Criticality related to English } \\
\text { as lingua franca }\end{array}$ & Quotations: the description of critical incident by the subsidiary staff \\
\hline $\begin{array}{l}\text { Requesting documents in English from the } \\
\text { HQ. }\end{array}$ & $\begin{array}{l}\text { The Chinese staff's low } \\
\text { English proficiency in written } \\
\text { communication. }\end{array}$ & $\begin{array}{l}\text { "The case studies we got from the HQ were full of misspellings or grammatical errors. We often ended up with revising the document } \\
\text { line by line over and over again before the material could be used for the marketing purpose" (\#22 European). } \\
\text { "I have difficulty communicating with the Chinese delivery team because of the English... What happens to me frequently is they do } \\
\text { not understand what kind of information I requested, nor do I understand what they tried to tell in the report or email" (\#6 Australian). }\end{array}$ \\
\hline $\begin{array}{l}\text { Understanding what the Chinese staff are } \\
\text { trying to say in the meeting. }\end{array}$ & $\begin{array}{l}\text { The Chinese staff's low } \\
\text { English proficiency in verbal } \\
\text { communication }\end{array}$ & $\begin{array}{l}\text { "Most of their oral English is not up to the professional level. You do not know what they are saying after 1-hour meeting. That is } \\
\text { really time-wasting" (\#19 European). } \\
\text { "In one conference call where our potential client was involved, we were promoting our service with our best effort. But our Chinese } \\
\text { project managers could not answer the client's question or participate in the discussion with proper English. What we got was a } \\
\text { prolonged silence from the China side where most of team member might leave the meeting already" (\#6 Australian). }\end{array}$ \\
\hline $\begin{array}{l}\text { Communicating ideas, technical jargons } \\
\text { and business terms }\end{array}$ & $\begin{array}{l}\text { The difficulty of explaining } \\
\text { ideas with the English that the } \\
\text { non-native speakers could } \\
\text { understand. }\end{array}$ & $\begin{array}{l}\text { "Sometimes I have to use different accent, speed and style of speech in order to make myself understood for the Chinese colleagues. It } \\
\text { is quite weird o think I need improve my English, my mother tongue, to communicate better in a company where English is the working } \\
\text { language" (\#1 Australian). } \\
\text { "When topic went deeper and involved technical jargons which did not have English words to cover that. I had to stop the original } \\
\text { agenda and explain every single technical term in English. As soon as I finished that difficult meeting, I instantly got } 5 \text { or } 6 \text { emails } \\
\text { asking about the technical terms I had explained before" (\#12 American). } \\
\text { "In U.S., everyone doing web design knows and complies with } 20 \% \text {-rule which means he or she needs to change } 80 \% \text { of image or } \\
\text { material from other designers' work. However, you need to explain this rule to the Chinese staff over and over again because everyone } \\
\text { in China seems to copy each other's work without any awareness" (\#10 American). }\end{array}$ \\
\hline $\begin{array}{l}\text { Understand the form of English used by } \\
\text { the Chinese staff }\end{array}$ & $\begin{array}{l}\text { The excessive verbosity creates } \\
\text { barriers to capture the core } \\
\text { message effectively. }\end{array}$ & $\begin{array}{l}\text { "It took me quite a long time to read through an email from HQ and I eventually realized that it was simply a meeting request" (\#1 } \\
\text { Australian). } \\
\text { "We are communicating each other for the business purpose. However, it gave me an impression that the Chinese staff takes } \\
\text { communication in English as beauty contest" (\#17 European). }\end{array}$ \\
\hline $\begin{array}{l}\text { Facing communication style that diverged } \\
\text { from 'fast', 'direct' and 'task-oriented' } \\
\text { communication code. }\end{array}$ & $\begin{array}{l}\text { The difference in implicit } \\
\text { communication rules. }\end{array}$ & $\begin{array}{l}\text { "There were a few bugs in the testing system, but they did not let our onsite-team or customer representative know about them. Then } \\
3 \text { days before the delivery date, and when they realized they could not sort out the problem themselves, they approached us and said } \\
\text { "we have got a problem" (\#12 American). } \\
\text { "I attended a meeting with business managers mostly from the HQ to discuss the company's new service strategy. However, the meeting } \\
\text { seemed to flow without any direction. Lot of things people were talking and explaining were not directly relevant to the meeting } \\
\text { agenda" (\#22 European). } \\
\text { "In Australian unit, I can speak out, question and suggest my colleagues including my boss without any fears. I do not see similar } \\
\text { environment in HQ where I had a hard time telling project managers when they have not done their job properly" (\#1 Australian). }\end{array}$ \\
\hline
\end{tabular}


Table 4: The coding scheme and empirical evidence for the reported emotions.

\begin{tabular}{|c|c|c|c|c|c|}
\hline Type of emotion & The Guiding appraisal & Subjective feeling cues & Expressive cues & Behavioral cues & Motivational cues \\
\hline $\begin{array}{l}\text { ANGER: a perceived } \\
\text { wrongdoing where } \\
\text { blame goes to others } \\
\text { and the focal individual } \\
\text { has the potential to } \\
\text { correct the situation }\end{array}$ & $\begin{array}{l}\text { unpleasant state, certainty } \\
\text { about the situation, high } \\
\text { control potential, unfair } \\
\text { treatment. }\end{array}$ & injustice, offence & $\begin{array}{l}\text { brows lowered, square } \\
\text { mouth; cutting words }\end{array}$ & yell, hit, criticize & move against the offender \\
\hline $\begin{array}{l}\text { Anger with the } \\
\text { Chinese speaking } \\
\text { employee's code- } \\
\text { switching }\end{array}$ & $\begin{array}{l}\text { "The meeting was } \\
\text { conducted in English. Then } \\
\text { few Chinese words popped } \\
\text { up at the middle of meeting. } \\
\text { Without any explanation in } \\
\text { English or asking me any } \\
\text { question, the meeting } \\
\text { suddenly changed into a } \\
\text { prolonged Chinese } \\
\text { conversation. When I } \\
\text { insisted an explanation, I } \\
\text { was only given less than } 5 \\
\text { or } 6 \text { sentences to cover } \\
\text { their } 30-\text { min discussion. } \\
\text { That was very rude as they } \\
\text { can speak English and knew } \\
\text { the English was the } \\
\text { language for the meeting" } \\
\text { (Interview, \#16, American) }\end{array}$ & $\begin{array}{l}\text { "It did not feel good at all, } \\
\text { it was felt that they (i.e., } \\
\text { Chinese staff) did not care } \\
\text { about your opinion or even } \\
\text { your physical presence in } \\
\text { the communication"” } \\
\text { (Interview, \#21 European). } \\
\text { "I do not feel it is right or } \\
\text { acceptable for the HQ staff } \\
\text { who break the English-only } \\
\text { policy they had set up" } \\
\text { (Interview, \#3 Australian) }\end{array}$ & $\begin{array}{l}\text { The facial expressions of } \\
\text { American sales were } \\
\text { characterized by tight } \\
\text { jaws, clenched teeth, a } \\
\text { clear vertical lines } \\
\text { between lowered browns } \\
\text { when the Webinar was } \\
\text { suddenly changed into a } \\
\text { Chinese conversation } \\
\text { (Participant } \\
\text { Observation) } \\
\text { A chain of emails in } \\
\text { Chinese was followed by } \\
\text { the response from an } \\
\text { Australian project } \\
\text { manager with two } \\
\text { capitalized words: } \\
\text { "ENGLISH PLEASE!" } \\
\text { (Documentary Data) }\end{array}$ & $\begin{array}{l}\text { One Australian } \\
\text { participant walked out of } \\
\text { the tele-conference, } \\
\text { saying in a very strong } \\
\text { tone "I had enough with } \\
\text { them speaking Chinese!" } \\
\text { (Participant Observation) } \\
\\
\text { "But if they do not make } \\
\text { an effort to practice the } \\
\text { language policy, I felt } \\
\text { they might not care about } \\
\text { their work" (Interview, } \\
\text { \#19 European) }\end{array}$ & $\begin{array}{l}\text { "I just told those } \\
\text { 'trouble-makers' in the } \\
\text { meeting, like...if you guys } \\
\text { carry on speaking } \\
\text { Chinese, May I ask you to } \\
\text { leave this English-only } \\
\text { meeting now" (Interview, } \\
\text { \#2 Australian) } \\
\\
\text { One US-based project } \\
\text { lead raised his voice and } \\
\text { cut off the discussion on } \\
\text { the Chinese side: "Listen, } \\
\text { guys, I can't carry on } \\
\text { with this meeting if it is } \\
\text { going to be in Chinese" } \\
\text { (Participant Observation) } \\
\text { The meeting requests } \\
\text { from the foreign } \\
\text { subsidiary often } \\
\text { highlighted "Full English } \\
\text { Translation" of } \\
\text { conference call } \\
\text { (Documentary Data) }\end{array}$ \\
\hline
\end{tabular}




\begin{tabular}{|c|c|c|c|c|c|}
\hline Type of emotion & The Guiding appraisal & Subjective feeling cues & Expressive cues & Behavioral cues & Motivational cues \\
\hline $\begin{array}{l}\text { RESENTMENT: } \\
\text { forced engagement } \\
\text { with particular } \\
\text { situation or behavior } \\
\text { because of no other } \\
\text { choices } \\
\text { Resentment towards } \\
\text { the Chinese managers } \\
\text { for not fulfilling the } \\
\text { English mandate }\end{array}$ & $\begin{array}{l}\text { unpleasant state, certainty } \\
\text { about the situation, unfair } \\
\text { treatment. } \\
\text { "As I am new and rely on } \\
\text { the Chinese team for the } \\
\text { information that I'm not } \\
\text { aware of, it's difficult to } \\
\text { tell them stick to } \\
\text { English. ...Instead, you } \\
\text { have to ask favor and wait } \\
\text { for someone in China to } \\
\text { give you that information } \\
\text { in English. It was not a } \\
\text { nice feeling as it puts you } \\
\text { in the position of } \\
\text { submission." (Interview, } \\
\text { \#11 American) }\end{array}$ & $\begin{array}{l}\text { feel forced to engage with } \\
\text { particular situation or } \\
\text { behavior; inequity } \\
\text { "To understand company's } \\
\text { big data service, I have to } \\
\text { beg my Chinese colleagues } \\
\text { speak or write in a form of } \\
\text { English I can understand } \\
\text { or somebody there [HQ] } \\
\text { can really help me to } \\
\text { understand their English" } \\
\text { (Interview, \#8 American) } \\
\text { "There are still some } \\
\text { people [in HQ] who are the } \\
\text { real experts in the service I } \\
\text { am trying to promote in } \\
\text { Europe. However, I can't } \\
\text { speak to them directly as } \\
\text { they don't want to speak a } \\
\text { foreign language at all" } \\
\text { (Interview, \#21, European) }\end{array}$ & $\begin{array}{l}\text { speaking in a sarcastic way; } \\
\text { bitter facial expression; body } \\
\text { gestures related to passive } \\
\text { resistance } \\
\text { "There is very, very few } \\
\text { English-speaking staff in } \\
\text { China HQ where English is } \\
\text { introduced as our official } \\
\text { working language. Quite } \\
\text { often, they [HQ staff] } \\
\text { response to my email in } \\
\text { Chinese even I write to them } \\
\text { in English." (Interview, \#10 } \\
\text { American) } \\
\text { "From an objective } \\
\text { perspective, speaking } \\
\text { English should make them } \\
\text { look more like a real } \\
\text { manager in an international } \\
\text { company." (Interview, \#4 } \\
\text { Australian) } \\
\text { As project managers were } \\
\text { talking each other in } \\
\text { Chinese, their Australian } \\
\text { counterparts remained silent } \\
\text { and polite in the auto- } \\
\text { conference but occasionally } \\
\text { displayed the body language } \\
\text { such as stiffened face, } \\
\text { crossing arms, rolling the } \\
\text { eyes, looking away from the } \\
\text { computer screen } \\
\text { (Participant Observation) }\end{array}$ & $\begin{array}{l}\text { indirect criticism; } \\
\text { render faint praise } \\
\text { "The top managers are } \\
\text { trying to push as much } \\
\text { as English uses } \\
\text { because we try to be a } \\
\text { global company. My } \\
\text { experience shows our } \\
\text { competitors seem to } \\
\text { have done better in } \\
\text { terms of language } \\
\text { issues" (Interview, \#22 } \\
\text { European) } \\
\text { "Having to go through } \\
\text { all the agonies, I think } \\
\text { the corporate HR } \\
\text { should seriously } \\
\text { rethink its current } \\
\text { hiring and promotion } \\
\text { practice regarding the } \\
\text { manager's English } \\
\text { fluency. Otherwise, it } \\
\text { will be a very big issue } \\
\text { to keep our non- } \\
\text { Chinese talents" } \\
\text { (Interview, \#21, } \\
\text { European) }\end{array}$ & $\begin{array}{l}\text { undermine someone who } \\
\text { has benefited unfairly or } \\
\text { undeservedly } \\
\text { "Quite a few managers in } \\
\text { here [Australia] reported } \\
\text { to me that their Chinse } \\
\text { managers are deliberately } \\
\text { ignoring their requests or } \\
\text { advices simply because } \\
\text { they can't speak Chinese" } \\
\text { (Interview, \#2 Australian) } \\
\\
\text { On internal staff forum, } \\
\text { the words such as "double } \\
\text { standard", "bamboo } \\
\text { ceiling", "lack of } \\
\text { commitment" were posted } \\
\text { by the anonymous foreign } \\
\text { staff to comment the } \\
\text { Chinese managers' stance } \\
\text { towards the English } \\
\text { mandate (Documentary } \\
\text { Data) }\end{array}$ \\
\hline
\end{tabular}




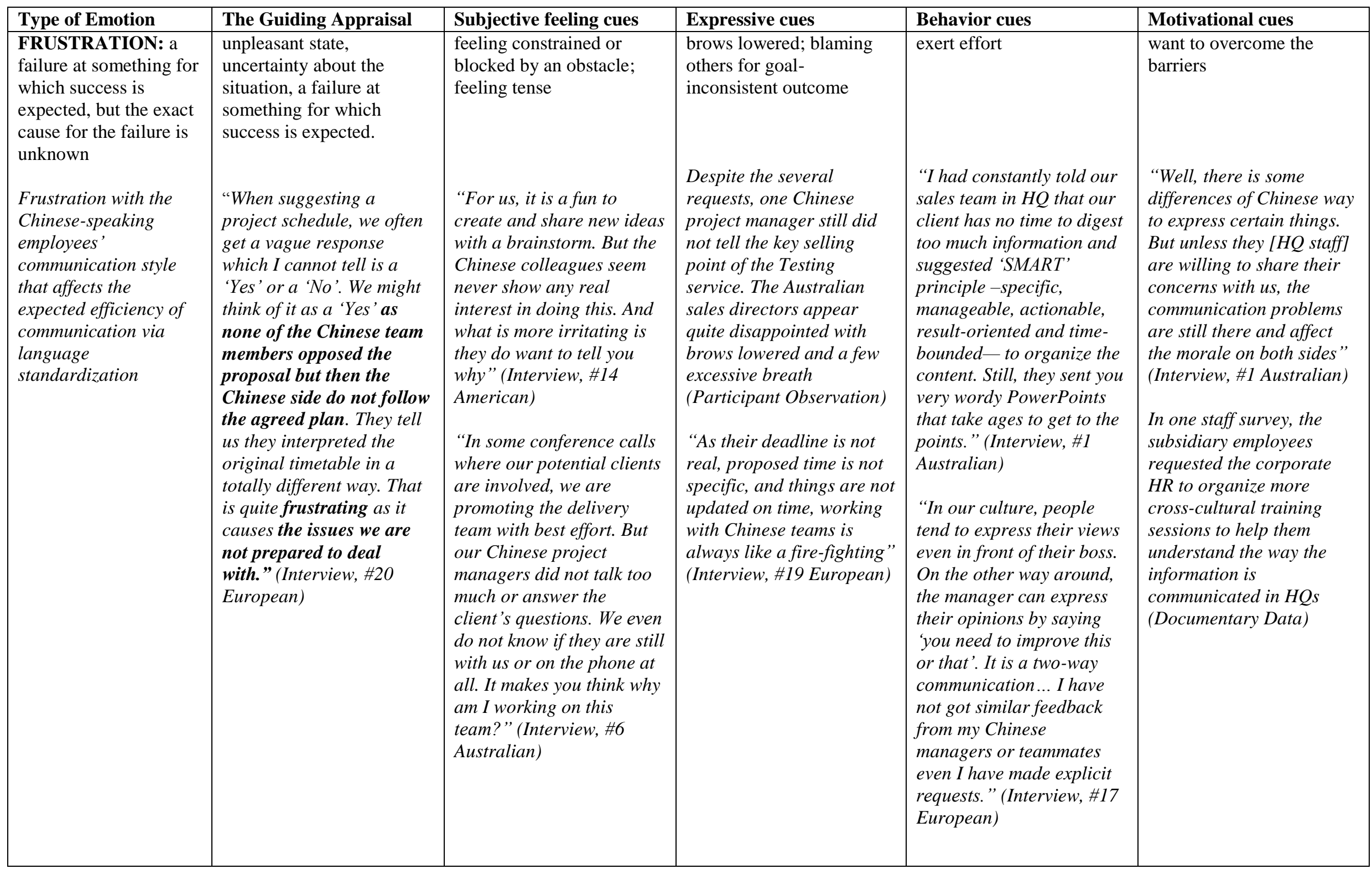




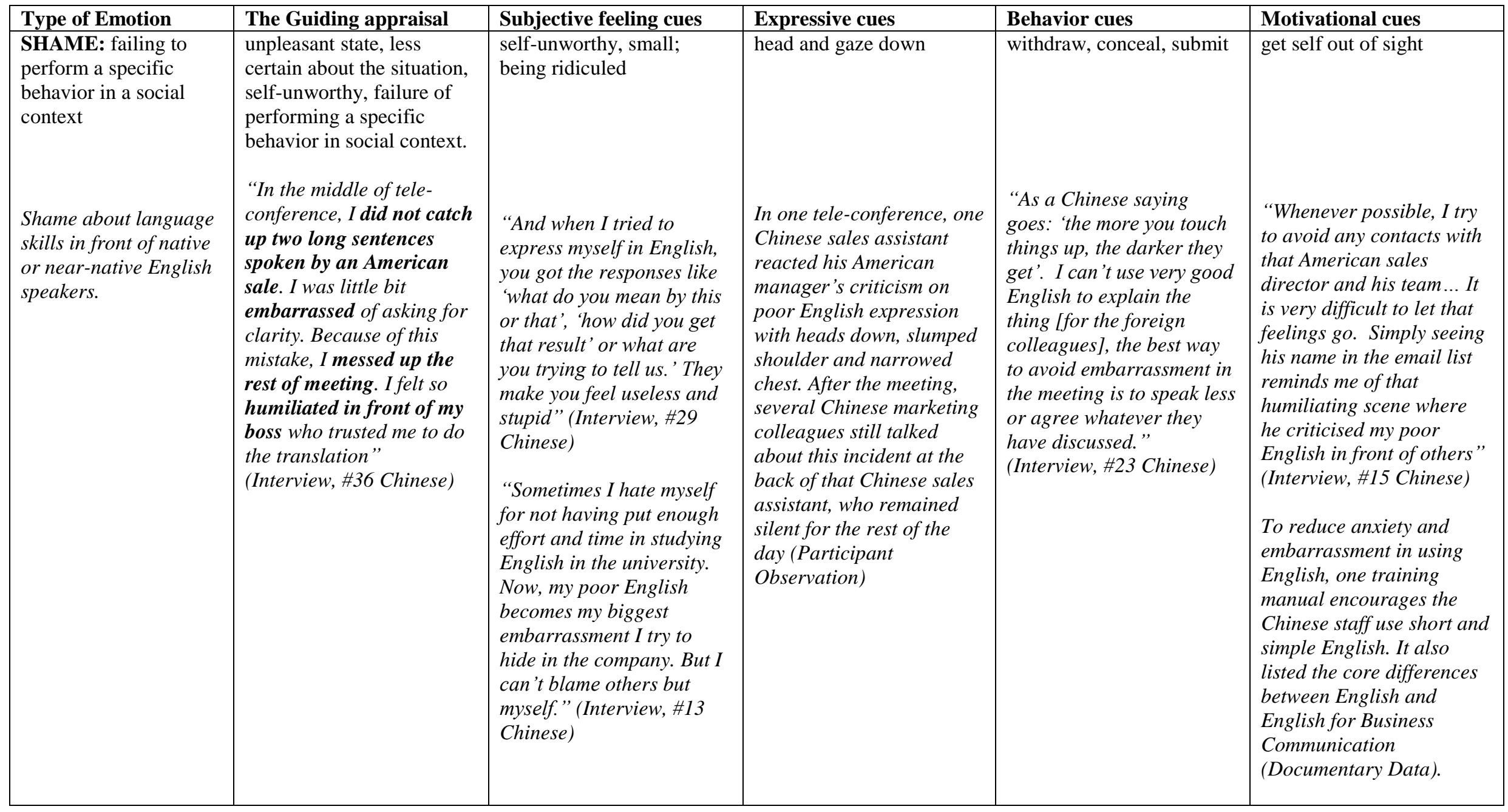




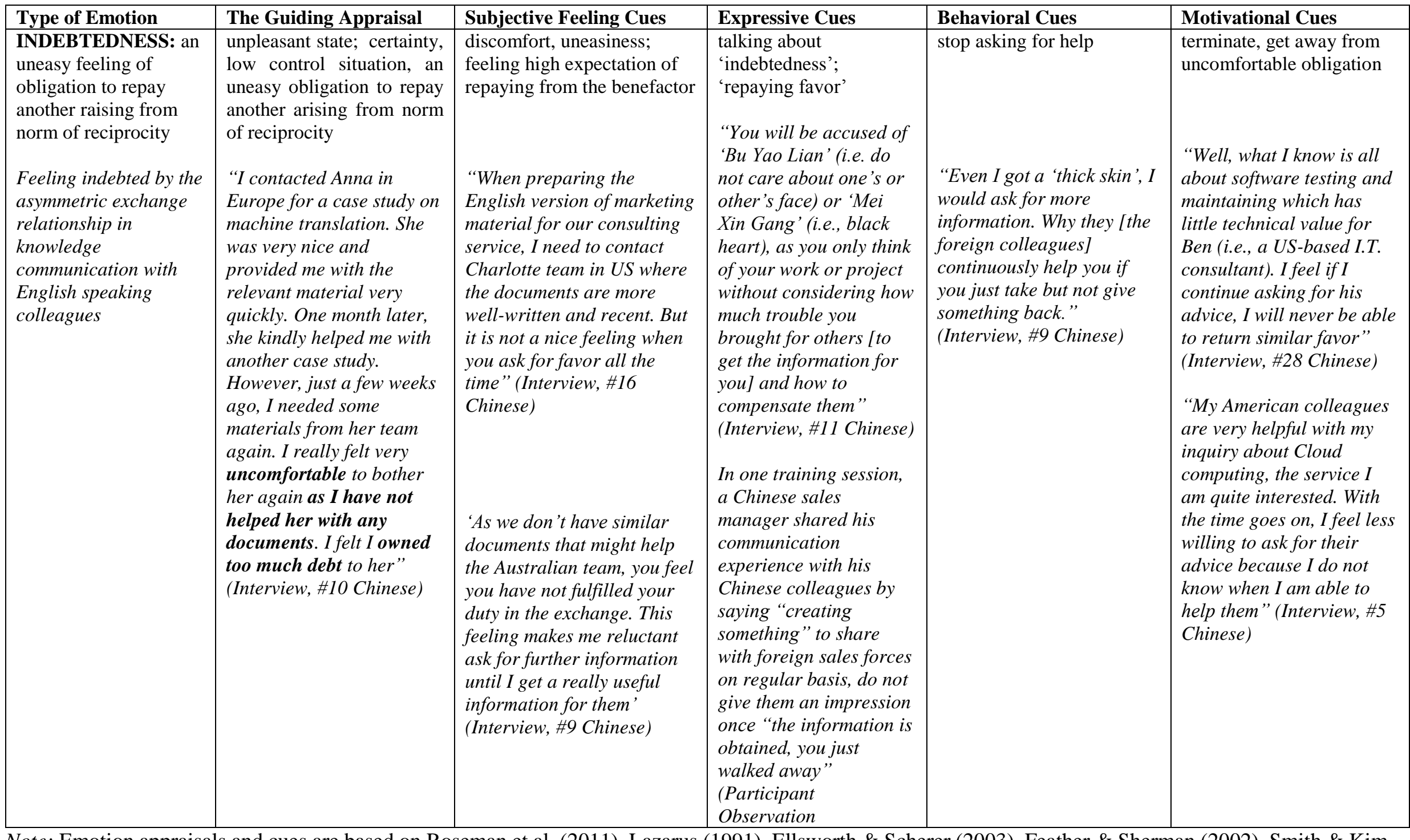

Note: Emotion appraisals and cues are based on Roseman et al. (2011), Lazarus (1991), Ellsworth \& Scherer (2003), Feather \& Sherman (2002), Smith \& Kim (2007), Neu (2009), Tangney et al. (1996), Watkins et al. (2006). 